\title{
Developing and Demonstrating Climate Indicators for Monitoring the Changing Water Cycle
}

\author{
Xia Feng and Paul Houser \\ Department of Geography and Geoinformation Science, George Mason University, Fairfax, VA 22030, USA \\ Correspondence should be addressed to Xia Feng; xia.feng@noaa.gov
}

Received 8 June 2015; Revised 17 October 2015; Accepted 19 October 2015

Academic Editor: Christophe Cudennec

Copyright ( $) 2016$ X. Feng and P. Houser. This is an open access article distributed under the Creative Commons Attribution License, which permits unrestricted use, distribution, and reproduction in any medium, provided the original work is properly cited.

\begin{abstract}
In this study, we developed a suite of spatially and temporally scalable Water Cycle Indicators (WCI) to examine the long-term changes in water cycle variability and demonstrated their use over the contiguous US (CONUS) during 1979-2013 using the MERRA reanalysis product. The WCI indicators consist of six water balance variables monitoring the mean conditions and extreme aspects of the changing water cycle. The variables include precipitation $(P)$, evaporation $(E)$, runoff $(R)$, terrestrial water storage $(d S / d t)$, moisture convergence flux $(C)$, and atmospheric moisture content $(d W / d t)$. Means are determined as the daily total value, while extremes include wet and dry extremes, defined as the upper and lower 10th percentile of daily distribution. Trends are assessed for annual and seasonal indicators at several different spatial scales. Our results indicate that significant changes have occurred in most of the indicators, and these changes are geographically and seasonally dependent. There are more upward trends than downward trends in all eighteen annual indicators averaged over the CONUS. The spatial correlations between the annual trends in means and extremes are statistically significant across the country and are stronger for $P, E, R$, and C compared to $d S / d t$ and $d W / d t$.
\end{abstract}

\section{Introduction}

The Intergovernmental Panel on Climate Change (IPCC) stated in its Fifth Assessment Report (AR5) that the global mean surface temperature has increased by about $0.85^{\circ} \mathrm{C}$ over the twentieth century and this increase is likely due to the enhancement of the greenhouse effect [1]. There is growing evidence that anthropogenic warming would induce an intensification of the global hydrological cycle that produces increased atmospheric moisture content, faster evaporation, more precipitation and runoff, leading to exacerbation of hydrologic extremes of flooding and droughts, and redistribution of precipitation from the midlatitudes to high and low latitudes [2-9]. Because of the central importance of water in the Earth system, any changes in mean, variability, and extremes of water cycle would have profound impact on our society and environment. It is essential to closely monitor water cycle changes and improve our knowledge of how the water cycle responds to climate change.

Tools for monitoring climate variability and change have been developed primarily through the use of indicators.
Indicators usually are measurements or calculations that represent the important features of the status and trend of climate system and are often used to guide both research and decisions [10]. There are several commonly used climate change indictors across the US and the globe. Karl et al. [11] introduced a combined Climate Extremes Index (CEI) to quantify observed changes in multiple types of climate extremes within the contiguous US (CONUS). The CEI is composed of five components measuring the fraction area of the CONUS that experiences extremes outside the 90th/10th percentile in the maximum and minimum temperature, extreme 1-day precipitation, wet/dry days, and the Palmer Drought Severity Index (PDSI). A revised version of the CEI from Gleason et al. [12] is calculated operationally for different season and year by the US National Ocean and Atmospheric Administration (NOAA). The US Drought Monitor (USDM) is one of the widely used drought indices that incorporates multiple data sources and derivative products from local to national scales [13]. The USDM utilizes a unique classification system from D0-D4 representing 30th, 20th, 10th, 5th, and 2nd percentile to measure the strength 
of drought. The Expert Team on Climate Change Detection and Indicators (ETCCDI) was established as a joint venture of the World Meteorological Organization Commission for Climatology $(\mathrm{CCl})$ and the World Climate Research Program Climate Variability and Predictability (CLIVAR) program to develop climate change indicators focusing on extreme events [14]. In total, 27 indicators are defined to provide a comprehensive overview of the changes in temperature and precipitation extremes. The ETCCD identifies most of the indicators by means of absolute, threshold, percentile, and duration values based on daily climate data.

Most studies, however, have addressed only the extreme aspect of water cycle with main focus on precipitation related climate change. To our knowledge, very few studies have been directed toward conducting a comprehensive analysis of changes in many aspects of water cycle in a warming climate. In this work, we propose a set of indicators to identify warming induced changes to several key water balance variables across the CONUS using a global reanalysis dataset. They are obtained at a grid point, a region, and the entire globe over annual, seasonal, and long-term time scales; that is, they are spatially and temporally scalable. This design flexibility is valuable for monitoring regional, continental, and global water cycle variability and hence it is important for decision-making associated with climate change. Six water balance variables are selected in this study, precipitation, evaporation, runoff, moisture convergence flux, atmospheric moisture content, and terrestrial water storage. To provide a general picture of water cycle changes, we detect trend in the indicators of these water variables and determine if existing trends are statistically significant.

The remaining paper is organized as follows. The methodology is briefly described in Section 2. The results are presented in Section 3, followed by the conclusions and discussions in Section 4.

\section{Methodology}

2.1. Data. Reanalyses have the advantage of generating complete global coverage over long time periods, thus providing a potential source for studying long-term changes in water cycle especially for regions where the station data are spare or unavailable. Reanalysis data have recently been used in assessing the trends in climate extreme indicators in conjunction with station and model data [15-17]. We are thus motivated to utilize the reanalysis product to monitor the changes in the different aspects of the water cycle.

The water cycle related variables are obtained from the Modern Era Retrospective-Analysis for Research and Applications (MERRA [18]), a state-of-the-art reanalysis that provides the multiyear estimates of atmospheric conditions and land surface fields. MERRA reanalysis is generated by the NASA Global Modeling and Assimilation Office (GMAO) using the Goddard Earth Observing System version 5 (GEOS-5) atmospheric GCM through a threedimensional variational (3DVAR) system. Besides in situ observations, MERRA also assimilates satellite observations, including Special Sensor Microwave Imager (SSM/I) radiances, TIROS Operational Vertical Sounder (TOVS) radiances, Atmospheric Infrared Sounder (AIRS) radiances, and scatterometer-based wind retrievals. MERRA uses Catchment Land Surface Model to improve prediction of the land surface processes through explicit modeling of subgrid-scale soil moisture variability and its effect on runoff and evaporation. The soil and vegetation parameters are obtained from the NASA GEOS-5 GCM. The MERRA data are available for the entire globe at $1 / 2^{\circ} \times 2 / 3^{\circ}$ spatial resolution with 72 hybrid vertical levels from 1979 to present.

MERRA has the unique Incremental Analysis Update (IAU) procedure, which could reduce the precipitation spindown problem and improve the stratospheric circulation. But the water vapor increment in MERRA is found to be affected by the introduction of Advanced Microwave Sounding Unit (AMSU-A) series in late 1998, which directly influences precipitation [19].

2.2. Definition of Water Cycle Indicators. The goal of this paper is to develop a suite of climate indicators to quantify the changes of water cycle in the context of warming climate. IPCC AR5 documented the observed twentieth century changes in the mean states of the different aspects of water cycle globally and regionally [1]. Their impact on society is felt through changes in variability and intensity. In addition to the mean, frequency, intensity, and duration of extreme events have also experienced significant changes as manifested by their adverse effect on infrastructure and community. Therefore, the Water Cycle Indicators (WCI) are developed in the study primarily for monitoring the mean conditions and extreme aspects of the changing water cycle. Specifically, the WCI indictors contain six water cycle components involved in the terrestrial and atmospheric water balance equations:

$$
\begin{gathered}
\frac{\partial S}{\partial t}=P-E-R, \\
\frac{\partial W}{\partial t}=C+E-P,
\end{gathered}
$$

where $S$ is terrestrial water storage term, $P$ is precipitation, $E$ is evaporation, $R$ is runoff, $W$ is atmospheric moisture content, and $C$ is the vertically integrated moisture convergence flux. The expressions of $W$ and $C$ are given by

$$
\begin{aligned}
W & =\frac{1}{g} \int_{0}^{P_{s}} q d p, \\
C & =\nabla \cdot \frac{1}{g} \int_{0}^{P_{s}} q \mathbf{V} d p,
\end{aligned}
$$

where $g$ is constant, $P_{s}$ is surface pressure, $q$ is specific humidity, and $\mathbf{V}$ is wind speed.

For each of six water balance variables in (1), we define three types of indicators: mean, dry and wet extremes. The mean indicator is calculated as a normalized anomaly:

$$
y_{t}=\frac{x_{t}-\bar{x}}{\sigma_{x}},
$$


TABLE 1: A suite of 18 indicators defined for mean, dry and wet extremes of $P, E, R, d S / d t, C$, and $d W / d t$.

\begin{tabular}{lcc}
\hline Mean indicator & Dry extreme indicator & Wet extreme indicator \\
\hline Mean $P$ & Lower 10th percentile of $P$ & Upper 10th percentile of $P$ \\
Mean $E$ & Lower 10th percentile of $E$ & Upper 10th percentile of $E$ \\
Mean $R$ & Lower 10th percentile of $R$ & Upper 10th percentile of $R$ \\
Mean $d S / d t$ & Lower 10th percentile of $d S / d t$ & Upper 10th percentile of $d S / d t$ \\
Mean $C$ & Lower 10th percentile of $C$ & Upper 10th percentile of daily $C$ \\
Mean $d W / d t$ & Lower 10th percentile of $d W / d t$ & Upper 10th percentile of $d W / d t$ \\
\hline
\end{tabular}

where $x_{t}$ is the water cycle variable at time $t$ and $\bar{x}$ and $\sigma_{x}$ are the climatological mean and standard deviation of $x_{t}$, respectively.

The extreme indicators are based on threshold defined as percentile. Accordingly, dry and wet extremes are determined as the lower 10th and upper percentile of distribution, respectively. Similar to (3), normalized time series of extremes is expressed as

$$
g_{t}=\frac{f_{t}-\bar{f}}{\sigma_{f}}
$$

where $f_{t}$ denotes the lower or upper 10th percentile value at time $t$ and $\bar{f}$ and $\sigma_{f}$ indicate the mean and standard deviation for corresponding dry or wet extremes.

The complete set of 18 WCI indicators is listed in Table 1. The defined indicators are aimed for the assessment of changes in many aspects of the water cycle including means and extremes. They are also helpful for a better understanding of climate change and gaining insight into the impact of changes on human activities and the environment. Additionally, these indicators could act as the reference data to evaluate future climate projections and hence to inform potential consequences of climate change to the public and policy makers. It is worthy to mention that this suite of indicators is scalable in space and time. They can be used to assess the broad scale changes in the water cycle. We mostly focus on our discussion to assessment of annual and seasonal aspects of regional change over the CONUS, while we must point out that the WCI indicators are also capable of global and continental analysis. The mean and extremes indicators are calculated from daily MERRA variables on annual and seasonal basis. For threshold indicators, the values of upper or lower 10th percentile are computed from daily time series over each calendar year or individual season during 19792013.

2.3. Estimate of Trend. To determine whether the trends in WCI indicators are significant, the nonparametric MannKendall (MK) $[20,21]$ test is adapted and applied. The MK test is widely used in assessing the significance of monotonic trends in hydrometeorological time series [2224]. This technique is a rank-based procedure, robust to the influence of outliers. It does not make any assumptions on the distribution of the data but requires that individual data values are uncorrelated. This condition is met by taking into account serial correlation in the residuals when conducting the statistical significance test. Under the null hypothesis $H_{0}$ that sample data, $X_{i}(i=1,2, \ldots, n)$, are independent and identically distributed random variables, the MK statistic $S$ is defined:

$$
S=\sum_{i=1}^{n-1} \sum_{j=i+1}^{n} \operatorname{sgn}\left(X_{j}-X_{i}\right)
$$

where sgn assigns $1,-0$, or -1 depending on whether $X_{j}-$ $X_{i}$ is positive, 0 , or negative. The standardized statistic $Z$ is approximated by the standard normal distribution with a mean of 0 and variance of 1 :

$$
Z= \begin{cases}\frac{(S-1)}{\sigma_{S}}, & \text { if } S>0, \\ 0, & \text { if } S=0 \\ \frac{(S+1)}{\sigma_{S}}, & \text { if } S<0,\end{cases}
$$

where the variance $\sigma_{S}$ is given by

$$
\sigma_{S}=\frac{1}{18}\left[n(n-1)(2 n+5)-\sum_{i=1}^{m} t_{i}\left(t_{i}-1\right)\left(2 t_{i}+5\right)\right],
$$

where $m$ is the number of tied groups and $t_{i}$ is the number of data points in $i$ th tied group. If $|Z|>Z_{1-\alpha / 2}$, the null hypothesis $H_{0}$ is rejected at significance level $\alpha$. A positive (negative) value of $Z$ indicates an upward (downward) monotone trend for the data $X_{i}$.

The magnitude of the trend is calculated as the slope $m$ of the Kendal-Theil robust line [25]:

$$
X=m t+b,
$$

where $t$ is time and the slope $m$ is expressed as

$$
m=\operatorname{median}\left(\frac{X_{i}-X_{j}}{i-j}\right), \quad \forall j<i,
$$

for $j=2,3, \ldots, n$. The intercept $b$ is solved by

$$
b=\operatorname{median}(X)-m * \text { median }(t) .
$$

2.4. Probability Density Function (PDF). In order to determine if there was a temporal change in the distributions of the above indicators over the study period, we compare the probability distributions of given indicator over two independent 17-year periods, 1979-1995 and 1996-2012. For 
TABLE 2: Percentage of significant upward (indicated by $\uparrow$ ) and significant downward (indicated by $\downarrow$ ) trends over the CONUS for indicators of $P, E, R, d S / d t, C$, and $d W / d t$.

\begin{tabular}{lccccccccccc}
\hline \multirow{2}{*}{ Indicators } & \multicolumn{2}{c}{ Annual } & \multicolumn{2}{c}{ Winter } & \multicolumn{2}{c}{ Spring } & \multicolumn{2}{c}{ Summer } & \multicolumn{2}{c}{ Fall } \\
& $\uparrow$ & $\downarrow$ & $\uparrow$ & $\downarrow$ & $\uparrow$ & $\downarrow$ & $\uparrow$ & $\downarrow$ & $\downarrow$ \\
\hline Mean $P$ & 20.2 & 29.6 & 27.1 & 8.0 & 11.5 & 33.8 & 17.2 & 32.3 & 8.4 & 17.9 \\
Mean $E$ & 22.6 & 33.0 & 35.2 & 16.0 & 22.4 & 30.8 & 16.9 & 32.4 & 17.5 & 22.6 \\
Mean $R$ & 14.2 & 25.6 & 12.9 & 19.1 & 4.8 & 31.5 & 7.3 & 18.3 & 9.3 & 15.1 \\
Mean $d S / d t$ & 4.0 & 1.6 & 17.3 & 8.9 & 16.0 & 15.5 & 31.6 & 10.0 & 5.2 & 17.5 \\
Mean $C$ & 19.2 & 27.1 & 3.9 & 35.2 & 14.4 & 32.6 & 26.8 & 24.4 & 22.1 & 10.8 \\
Mean $d W / d t$ & 0.4 & 0.4 & 2.0 & 29.1 & 23.1 & 8.2 & 14.2 & 6.7 & 5.6 & 5.5 \\
Dry extreme of $P$ & 2.1 & 21.9 & 2.9 & 6.0 & 1.4 & 5.9 & 2.9 & 1.6 & 0.4 & 7.4 \\
Dry extreme of $E$ & 35.1 & 14.3 & 27.5 & 8.1 & 19.7 & 21.6 & 11.7 & 35.9 & 12.2 & 18.6 \\
Dry extreme of $R$ & 2.6 & 6.2 & 1.3 & 1.6 & 0.6 & 2.2 & 0.5 & 1.0 & 0.4 & 1.8 \\
Dry extreme of $d S / d t$ & 34.6 & 13.0 & 25.0 & 21.2 & 26.7 & 10.4 & 25.0 & 11.7 & 27.0 & 20.1 \\
Dry extreme of $C$ & 11.5 & 27.0 & 6.0 & 17.9 & 11.1 & 23.5 & 11.0 & 29.0 & 17.7 & 10.3 \\
Dry extreme of $d W / d t$ & 0.8 & 43 & 6.2 & 18.1 & 5.7 & 19.7 & 3.1 & 32.8 & 9.0 & 13.4 \\
Wet extreme of $P$ & 19.9 & 24.2 & 23.7 & 7.1 & 17.2 & 18.2 & 15.7 & 26.4 & 9.4 & 19.2 \\
Wet extreme of $E$ & 21.0 & 29.5 & 28.9 & 24.4 & 18.8 & 25.4 & 19.5 & 22.7 & 19.8 & 27.1 \\
Wet extreme of $R$ & 12.2 & 26.7 & 10.6 & 18.1 & 8.3 & 26.0 & 7.1 & 22.6 & 8.9 & 21.2 \\
Wet extreme of $d S / d t$ & 12.6 & 30.3 & 18.2 & 8.8 & 17.9 & 15.9 & 11.9 & 25.8 & 5.1 & 28.6 \\
Wet extreme of $C$ & 30.2 & 12.2 & 8.9 & 22.4 & 10.8 & 19.7 & 24.9 & 10.8 & 22.8 & 6.7 \\
Wet extreme of $d W / d t$ & 37.6 & 1.3 & 20.6 & 5.6 & 17.1 & 12.3 & 31.5 & 2.9 & 14.4 & 8.6 \\
\hline
\end{tabular}

each WCI, PDF was obtained by binning annual (or seasonal) values and calculating the corresponding probabilities. The sum of area below PDF curve across all bins is normalized to 1 . We examine if the distribution for the period 1979-1995 differs from the distribution for 1996-2012. The nonparametric Kolmogorov-Smirnoff test is used to test whether the probability distributions of one specific indicator from two time periods are significantly different or not.

\section{Results}

One of the appealing features of the WCI indicators is the ability to analyze long-term changes in the water cycle at various temporal and spatial scales. In this section, we present spatial pattern of changes in WCI indicators and temporal variation of spatially averaged indicators to assess the annual and seasonal characteristics of water cycle changes over the CONUS.

3.1. Trends in Annual Indicators. Figure 1 shows the spatial maps of trend in mean and extremes indicators for six water balance components over the CONUS for the period 1979-2013 derived from MERRA. Regions where trend is statistically significant at the $5 \%$ level are denoted by hatching. The annual mean $P$ shows a significant tendency toward wetter conditions over a large part of east coast and west north central areas, whereas significant drying trends are located over central and west coast during the past 35 years. Previous observational studies by Kunkel et al. [26] reported local increase of annual $P$ in the central and southwest regions over 1931-1990 period, while Groisman et al. [27] found the increase in the central region with decrease over the southwestern area during 1900-2002. Since these studies used different time periods for trend analysis, their results cannot be directly compared with our results.

According to Table 2, 20.2\% of the CONUS shows significant upward trend in mean $P$ while $29.6 \%$ of the nation shows significant downward trend. The temporal evolution of each indicator averaged over the nation during 1979-2013 period is shown in Figure 2. The formula and red line represent the Kendall-Theil robust line in each panel. Nationally averaged, mean $P$ has slightly decreased by $\sim 0.008 /$ year (bot not significant) since 1979. Although several studies found a nationwide increase of annual total precipitation [26-28], they are based on different station data spanning a variety of time periods.

Dry extreme of $P$ is an indicator of extremely dry condition and exhibits a tendency toward drier conditions over southwest and northeast regions and conversely wetter conditions over the remaining country. However, these changes are small and mostly are not statistically significant. This general pattern is also reflected in the national time series (Figure 2) showing a nonsignificant decrease from 1979 to 2013. For $P$ wet extreme, a potential flood indicator, the trend patterns are remarkably similar to the changes of mean $P$. It can be seen that $19.9 \%$ of the nation has experienced significant increase of intense $P$ concentrated over the eastern and southern coastal regions as opposed to $24.2 \%$ with significant decrease predominantly occurred over northwest and central regions between 1979 and 2013. Similar to mean $P$, the nationally averaged $P$ wet extreme shows a decline over the past several decades with steeper slope than mean and dry extreme indicators. Earlier observational studies of trends 

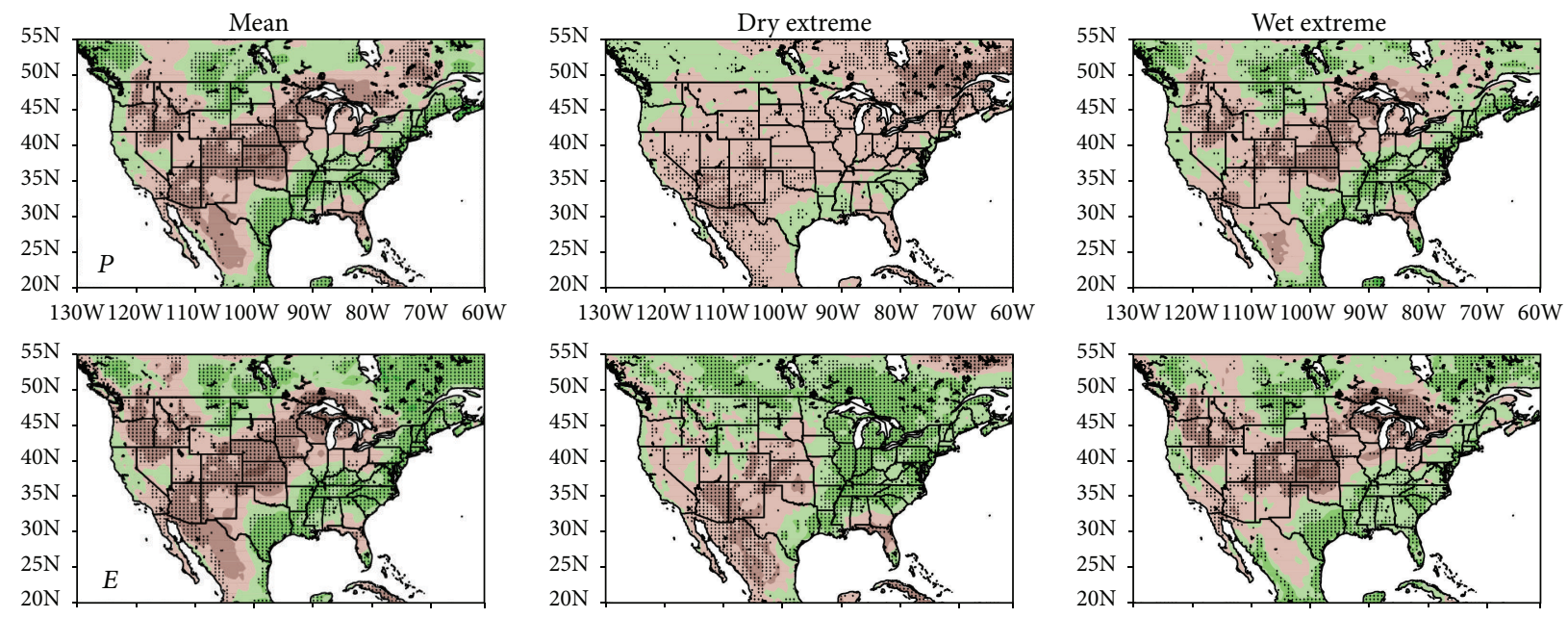

130W 120W 110W 100W 90W 80W 70W 60W
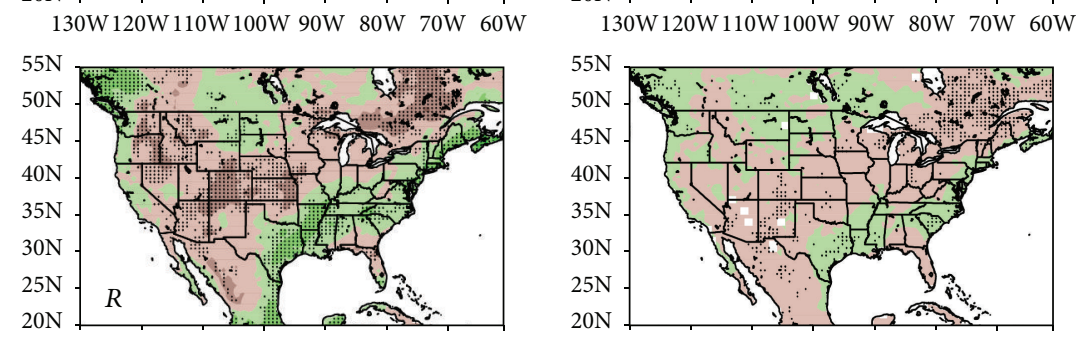

$130 \mathrm{~W} 120 \mathrm{~W} 110 \mathrm{~W} 100 \mathrm{~W} 90 \mathrm{~W} 80 \mathrm{~W} 70 \mathrm{~W} 60 \mathrm{~W}$

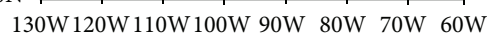

130W 120W 110W 100W 90W 80W 70W 60W

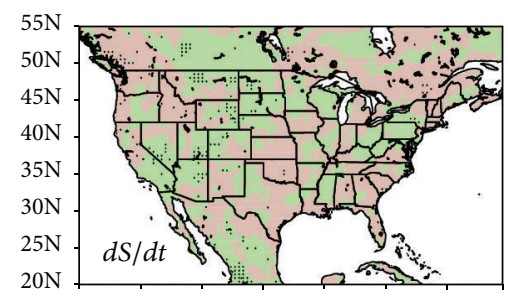

130W 120W 110W 100W 90W 80W 70W 60W
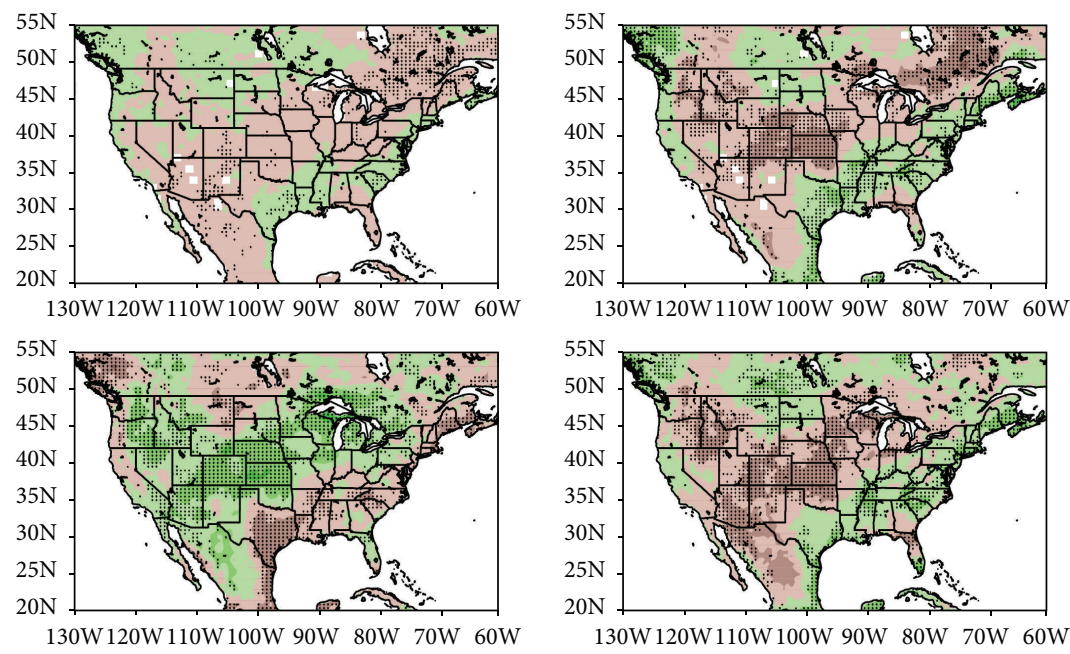

130W 120W 110W 100W 90W 80W 70W 60W
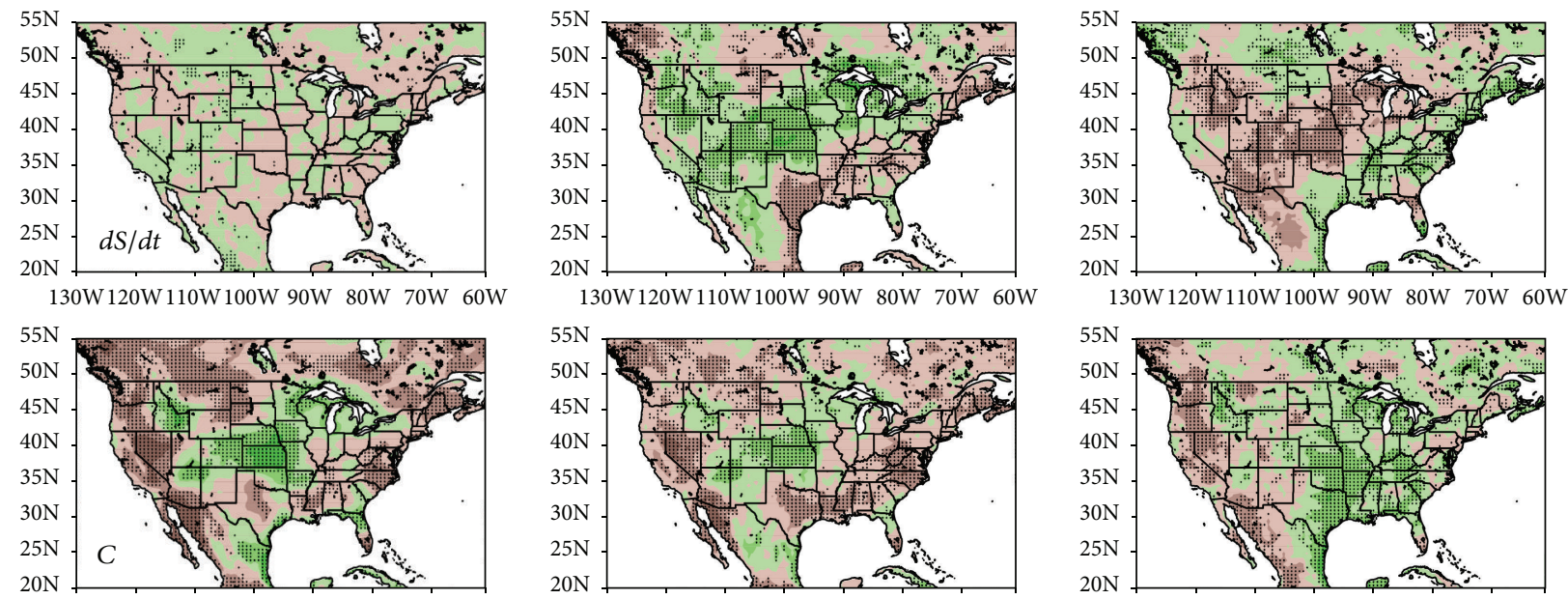

$130 \mathrm{~W} 120 \mathrm{~W} 110 \mathrm{~W} 100 \mathrm{~W} 90 \mathrm{~W} 80 \mathrm{~W} 70 \mathrm{~W} 60 \mathrm{~W}$

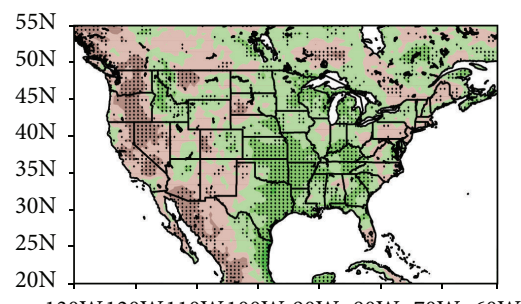

130W120W110W 100W 90W 80W 70W 60W
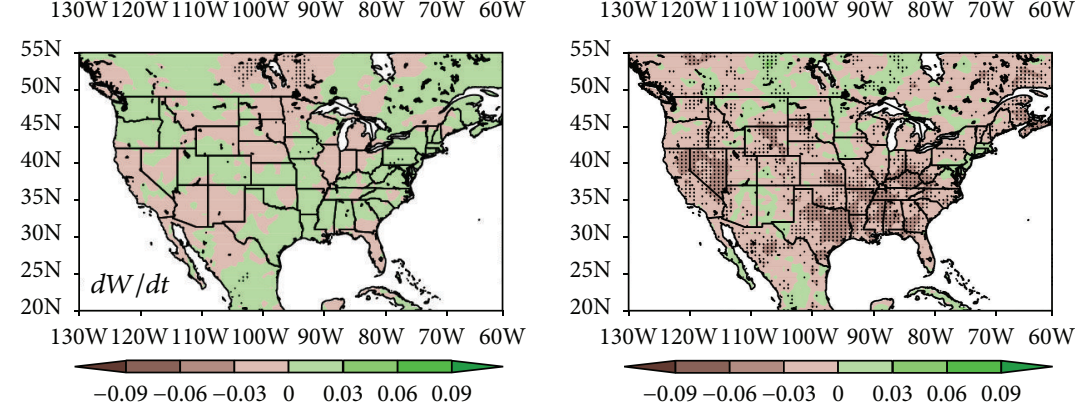

130W 120W 110W 100W 90W 80W 70W 60W

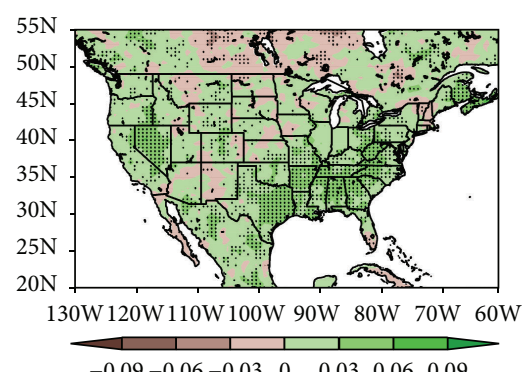

Figure 1: Trends (per year) in the annual WCI indicators of mean, dry extreme, and wet extreme of $P, E, R, d S / d t, C$, and $d W / d t$ for 1979-2013 in MERRA. Hatching indicates trends that are statistically significant at the $5 \%$ level. 

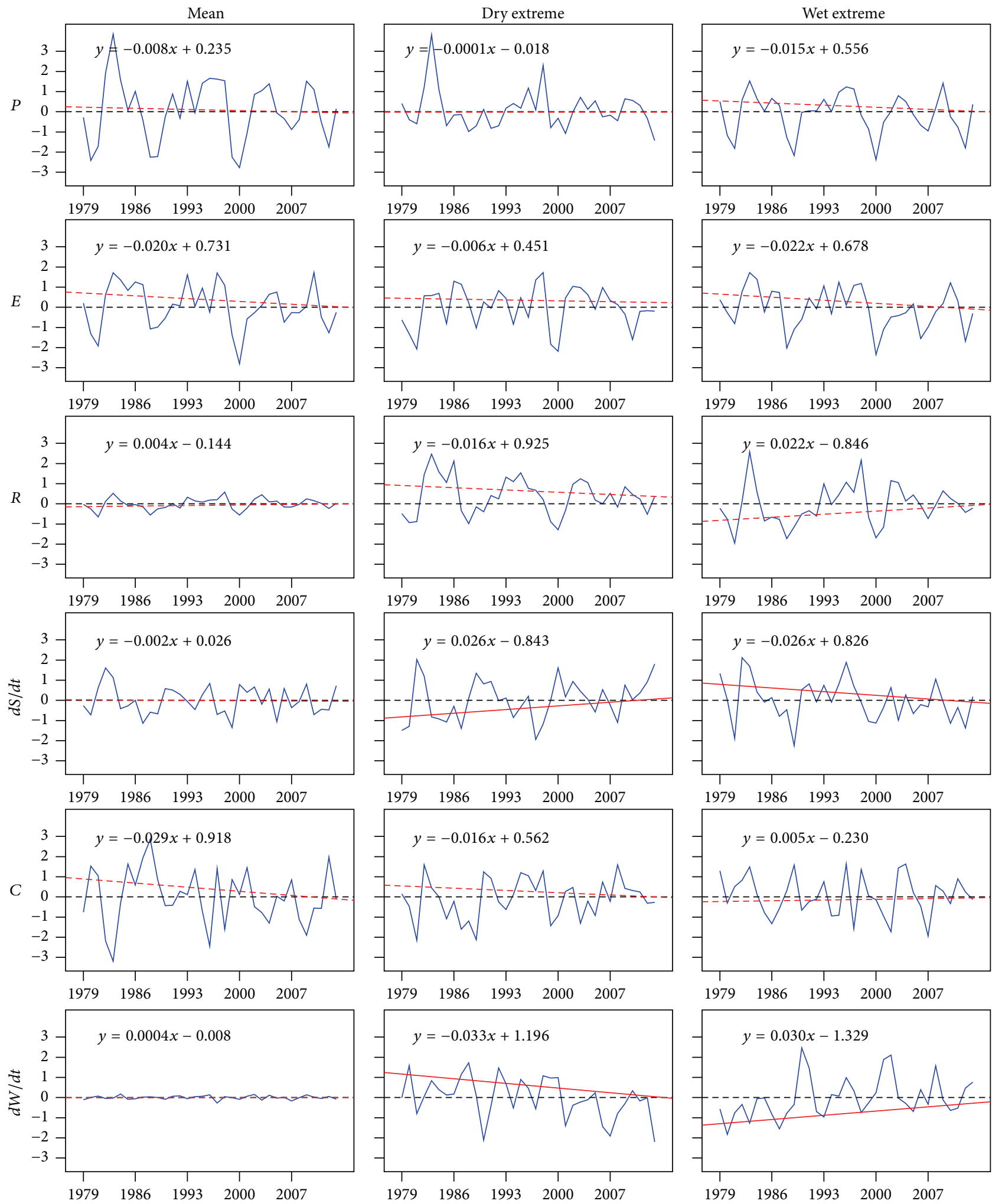

FIGURE 2: Annual time series of mean, dry extreme, and wet extreme WCI indicators of $P, E, R, d S / d t, C$, and $d W / d t$ for 1979-2013 in MERRA. Equation and red line in each panel represent the Kendall-Theil robust line. Solid and dash red lines indicate significant and nonsignificant trends at the $5 \%$ statistical level. 
TABLE 3: Spatial correlation between the trend in mean and extremes indicators of $P, E, R, d S / d t, C$, and $d W / d t$ over the CONUS. The coefficients are highlighted with asterisk mark if they are statistically nonsignificant at $5 \%$ level.

\begin{tabular}{lccccccccccc}
\hline \multirow{2}{*}{ Indicators } & \multicolumn{2}{c}{ Annual } & \multicolumn{2}{c}{ Winter } & \multicolumn{2}{c}{ Spring } & \multicolumn{2}{c}{ Summer } & \multicolumn{2}{c}{ Fall } \\
& Dry extreme & $\begin{array}{c}\text { Wet } \\
\text { extreme }\end{array}$ & $\begin{array}{c}\text { Dry } \\
\text { extreme }\end{array}$ & $\begin{array}{c}\text { Wet } \\
\text { extreme }\end{array}$ & $\begin{array}{c}\text { Dry } \\
\text { extreme }\end{array}$ & $\begin{array}{c}\text { Wet } \\
\text { extreme }\end{array}$ & $\begin{array}{c}\text { Dry } \\
\text { extreme }\end{array}$ & $\begin{array}{c}\text { Wet } \\
\text { extreme }\end{array}$ & $\begin{array}{c}\text { Dry } \\
\text { extreme }\end{array}$ & $\begin{array}{c}\text { Wet } \\
\text { extreme }\end{array}$ \\
\hline Mean $P$ & 0.39 & 0.93 & -0.15 & 0.87 & 0.45 & 0.86 & 0.29 & 0.92 & 0.16 & 0.86 \\
Mean $E$ & 0.57 & 0.91 & 0.83 & 0.92 & 0.78 & 0.92 & 0.92 & 0.93 & 0.70 & 0.94 \\
Mean $R$ & 0.35 & 0.90 & 0.13 & 0.88 & 0.24 & 0.87 & 0.26 & 0.84 & 0.15 & 0.89 \\
Mean $d S / d t$ & 0.09 & $0.03^{*}$ & 0.12 & 0.66 & 0.28 & 0.50 & 0.38 & 0.45 & -0.14 & 0.59 \\
Mean $C$ & 0.83 & 0.64 & 0.59 & 0.41 & 0.72 & 0.51 & 0.79 & 0.61 & 0.75 & 0.37 \\
Mean $d W / d t$ & -0.05 & 0.15 & -0.22 & 0.35 & 0.12 & $-0.02^{*}$ & $-0.01^{*}$ & 0.10 & 0.07 & -0.04 \\
\hline
\end{tabular}

in extreme indicators have revealed significant changes in extreme precipitation across the country in the regional [26$28]$ and global $[14,29,30]$ analysis. However, their definitions and thresholds of extremes are quite different from this study and thus make it difficult to directly compare our results with previous findings.

To further determine the relation between the mean and the extremes, we also calculated the spatial correlations between the annual trends in mean and extremes for each indicator over the CONUS (Table 3) using Pearson productmoment correlation. It is noted that the correlation coefficients for mean $P$ with respect to dry and wet extremes are 0.39 and 0.93 , respectively, which is consistent with their trends changes in Figures 1 and 2. The high correlation between the mean and wet extreme of precipitation is also in agreement with the findings of [26], who showed that most of the increase in annual precipitation is associated with more intense and frequent precipitation over the CONUS during the last sixty years.

The $E$ indicators exhibit similar patterns of changes to the trends of mean and wet extreme of $P$ over the 35-year period. A vast area of the Midwest also exhibits significant increase in dry extreme, leading to a larger percentage of the nation showing positive trend in dry extreme $(35.1 \%)$ than mean and wet extreme (22.6\% and $21 \%)$. Furthermore, each averaged $E$ indicator has stronger decreasing trend than the corresponding $P$ indicator with mean $E$ changing at the fastest rate (Figure 2). For $E$ indicators, the correlation is higher between mean and wet extreme than dry extreme (Table 3). Such relationship is in agreement with $P$ indicators but the correlation between mean and dry extreme is bigger in $E$ than $P$ due to more positive changes occurring in dry extreme of $E$.

Spatial distribution and correlation of trends in $R$ indicators agree well with the $P$ and $E$ indicators (Figure 1). However, trends of $R$ have smaller magnitude and lower level of statistical significance. This difference is also seen in Table 2, which shows smaller percentage of the nation identified as having significant trends in comparison with $P$ and $E$ indicators. In addition, the nationally averaged mean and wet extreme of $R$ show increasing trend in contrast to the downward trend in both $P$ and $E$ indicators. This is probably because more precipitation turns into runoff as $E$ shows smaller decreasing rate than $P$.
The significant increase of mean and dry extreme of $C$ has been observed over parts of central and southwest regions. These patterns are apparently opposite to the most of the indicators in above-mentioned three water balance variables. This is somewhat expected according to water balance equations (1). The wet extreme of $C$ shows a widespread and significant increase over much of the country, leading to more significant positive changes than significant negative change compared to the other two $C$ indicators (Table 2). Mean $C$ is highly correlated with each of extreme indices but dry extreme has a larger coefficient than wet extreme (0.83 0.64). Such relationship is also noted in the national series (Figure 2), which shows decreasing trend in mean and dry extreme indicators and increasing trend in wet extreme.

The trends in two water storage variables, $d S / d t$ and $d W / d t$, differ considerably from the other indicators. Most notably the mean trends appear spatially more heterogeneous and statistically not significant, resulting in fewer areas of significant changes (Table 2) and smaller national trends (Figure 2). In addition, dry extreme displays opposite changes with wet extreme for both $d S / d t$ and $d W / d t$, as evident from their spatial patterns, significance percentage, and national series. For these two water storage indicators, the mean and extremes have weaker relations compared to the other four water variables as evidenced by smaller and even nonsignificant correlation coefficients, for instance, mean and dry extreme of $d S / d t$.

Given the trends patterns identified by each of WCI indicators, we are interested in looking at the general picture of changes in water cycle variability. Figure 3 shows the sum of signs of annual trends from all 18 indicators across the county. Regions with positive sums are located along a large area over eastern coast, parts of north, northwest coast, and west with the maximum value exceeding 12 . In contrast, there are widespread and coherent negative values appearing over much of central, southwest, and large portion of northwest, where the maximum sum lies above 12 . This contrast pattern is pretty much consistent with annual trends in most of the indicators and further reinforces that water cycle displays varied geographical features associated with climate change.

To further illustrate the spatial scalability of the WCI indicators, we show in Figure 4 the time variations of indicators for water balance variables at two different spatial domains, a small region over the east coast (RG1 hereafter) and one 


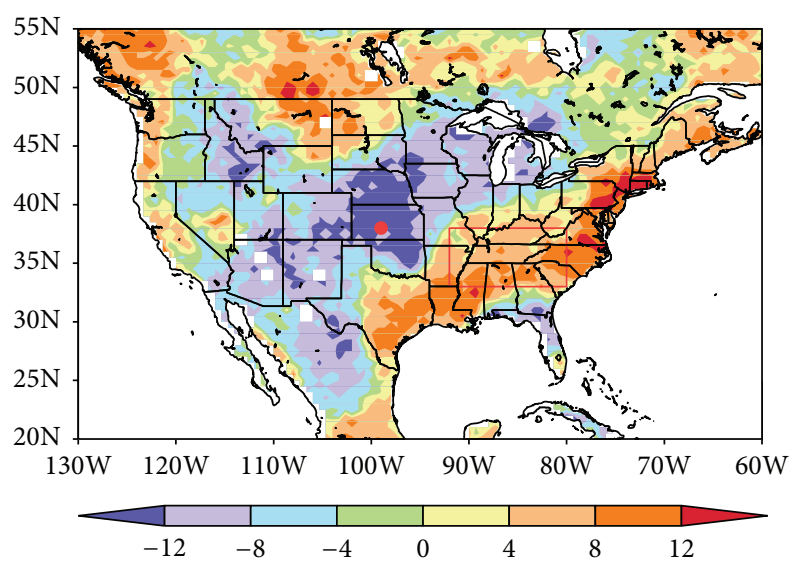

Figure 3: The sum of signs of annual trend changes of all $18 \mathrm{WCI}$ indicators over the CONUS.

grid in the central region (RG2 hereafter), denoted by red box and red dot in Figure 3, respectively. The region RG1 locates over the eastern region where positive changes of many WCI indicators have been observed, while RG2 locates in the swath of negative changes. Not surprisingly, there is significant increase in most of the indicators over the RG1 with several mean and dry extreme indicators showing decline over the 35 -year period. There is much more significant decreasing trend than significant increasing trend in the time series of indicators over RG2.

3.2. Trends in Seasonal Indicators. Besides spatial scalability, the WCI indicators are also scalable on different temporal regimes. In this section, we examine the trends in seasonal WCI indicators associated with climate change over the CONUS. Seasons are defined as follows: winter (December-January-February), spring (March-April-May), summer (June-July-August), and fall (September-OctoberNovember). The spatial patterns of trends (Figures 5 and 6) and time series (Figure 7) are presented for all indicators during summer and fall over the period of 1979-2013. Seasonal trends in all indicators are generally consistent with annual results but differing in magnitude and significance. We found that the spatial trends in $P$ and $E$ indicators during fall tend to agree well with the corresponding annual patterns, suggesting that the changes observed in annual indicators mainly are attributed by fall and, to a less extent, summer. For $R, C$, and $d W / d t$ indicators, annual trends are primarily affected more by summer changes, while spring (not shown) contributes to the annual change of $d S / d t$. The trends in dry extremes of $P$ and $R$ are mostly nonsignificant in all seasons with less than $9 \%$ of the nation showing significant changes in each season (Table 2). In general, the most significant changes occur in summer with the least significant changes appearing in fall. In addition, more areas exhibit positive changes for $P$, $E$, and $d S / d t$ indicators during winter (not shown) and for $C$ indicators during fall.

Generally, the national series show a mixed of upward and downward trends across the seasons although these trends are mostly nonsignificant (Figure 7). Overall, there are more positive changes than negative changes in winter and fall where at least two upward trends are observed in each of the $P, E, R$, and $d S / d t$ indicators. Notably, fall has the most positive trends in the mean and dry extreme indicators, while the most increased wet extreme events have occurred in winter. Large number of decreasing trends are found in spring and summer with four to five negative trends for each of mean and extremes indicators.

Throughout all seasons, trends in wet extremes of $P, E$, $R$, and $d S / d t$ are highly correlated with the means than the corresponding dry extreme (Table 3 ), which is opposite to $C$ indicators. The strongest relation occurs in $R$ indicators across all seasons with coefficients constantly above 0.7 . The correlation coefficients for $d S / d t$ are considerably small and nonsignificant except in fall, indicating the weakest relation between the mean conditions and the extremes.

Like annual analysis, we also combine the signs of trends of all 18 indicators for all seasons as shown in Figure 8. Overall, seasonal sums exhibit similar patterns to those observed in annual results. It is evident that summer generally appears to bear the most similarity to annual pattern with discernible differences in winter where parts of central and southwest show larger positive values. The results are in general consistent with the pattern of trends from individual index and further highlight the seasonal aspects of water cycle changes.

3.3. Decadal Changes in the PDFs. To further investigate the long-term changes in water cycle variability, we present the PDFs for annual WCI indicators for the periods 19791995 and 1996-2012 in Figure 9. For each index, time series from across the country are used to generate PDFs for each of the two periods. We found that the distributions of all the indicators from different time periods are significantly different. The figure indicates a small shift toward drying conditions associated with a shift toward decreased extremes in the $P$ indicators between 1996 and 2012 when compared to 1979-1995. There are also visible shifts in $E$ corresponding to decreased mean and wet extreme along with increased dry extreme. The distributions of the $R$ indicators show a marked reduction in the mean and extremes during the most recent decade. For $d S / d t$, the PDFs exhibit little change in the mean accompanied with slight increase in dry extreme and decrease in wet extreme. Mean and dry extreme of $C$ and $d W / d t$ have significantly decreased over the recent 17 -year period but the corresponding wet extremes have increased.

For all the indicators, we also calculated the PDFs in all the seasons over two different periods. During each season, the PDFs for the period 1979-1995 are statistically significant compared to those for the 1996-2012 period for every index. The changes in general are more pronounced in summer (Figure 10) with least changes generally occurring in fall (Figure 11). The $P$ PDFs for summer show a similar pattern of change to annual values although of larger magnitude. Means of $P$ in spring (not shown) and fall also exhibit a tendency toward drying conditions that is consistent with the annual change, whereas winter mean $P$ shows a shift toward wetter 

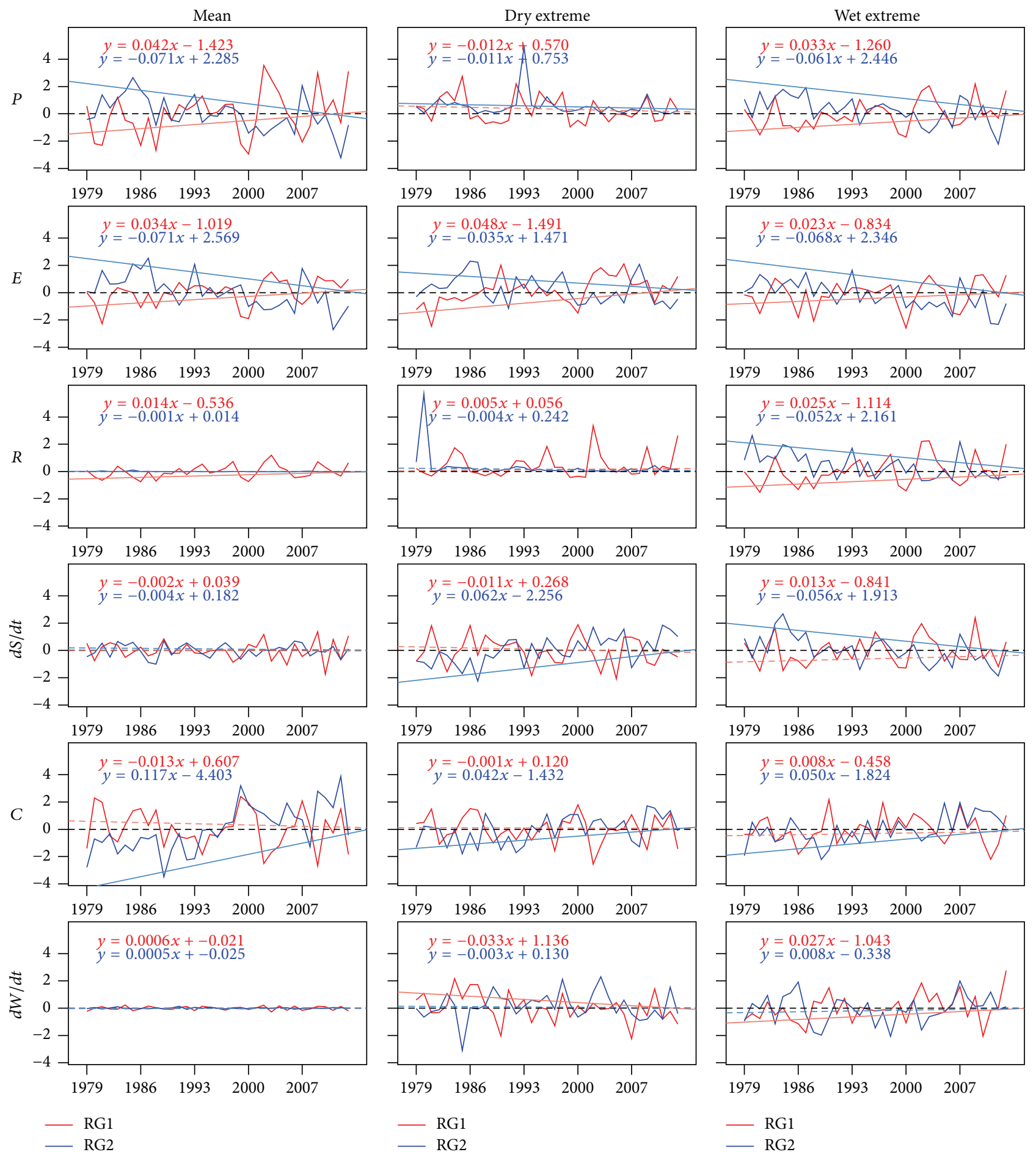

FIGURE 4: Same as Figure 2 but for RG1 and RG2, which are denoted by red box and red dot, respectively, in Figure 2. Red and blue lines indicate time series of indicators for RG1 and RG2, while light red and light blue represent the Kendall-Theil robust lines for RG1 and RG2.

conditions. Note that some seasonal extremes show nonGaussian distributions such as $P$ and $R$ in fall, which could affect the resulting significance test and make the results difficult to interpret. The largest changes in $R$ indicators are observed in spring and summer where the distributions of mean and extremes show apparent shifts. This is likely related to snowmelt and convective rainfall events induced runoff changes during these two seasons. The $d S / d t$ indicators have changed substantially throughout the seasons with visible shifts in the distributions. The PDFs of $C$ and $d W / d t$ in summer and winter are generally similar to annual patterns. 

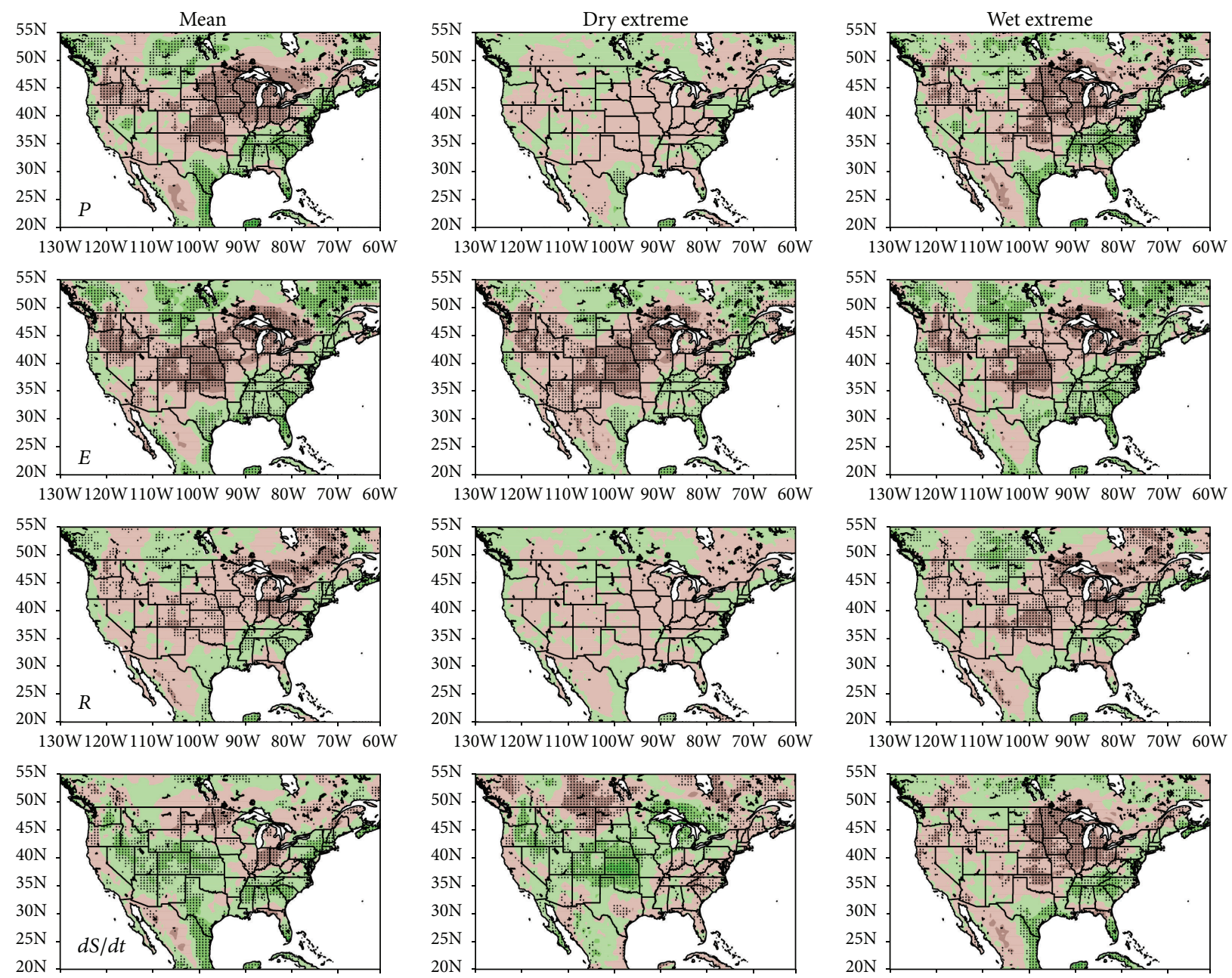

130W 120W 110W 100W 90W 80W 70W 60W

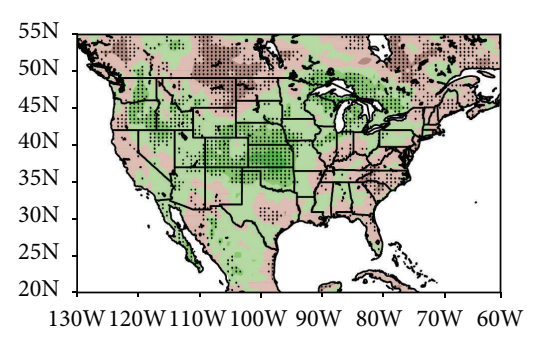

130W 120W 110W 100W 90W 80W 70W 60W
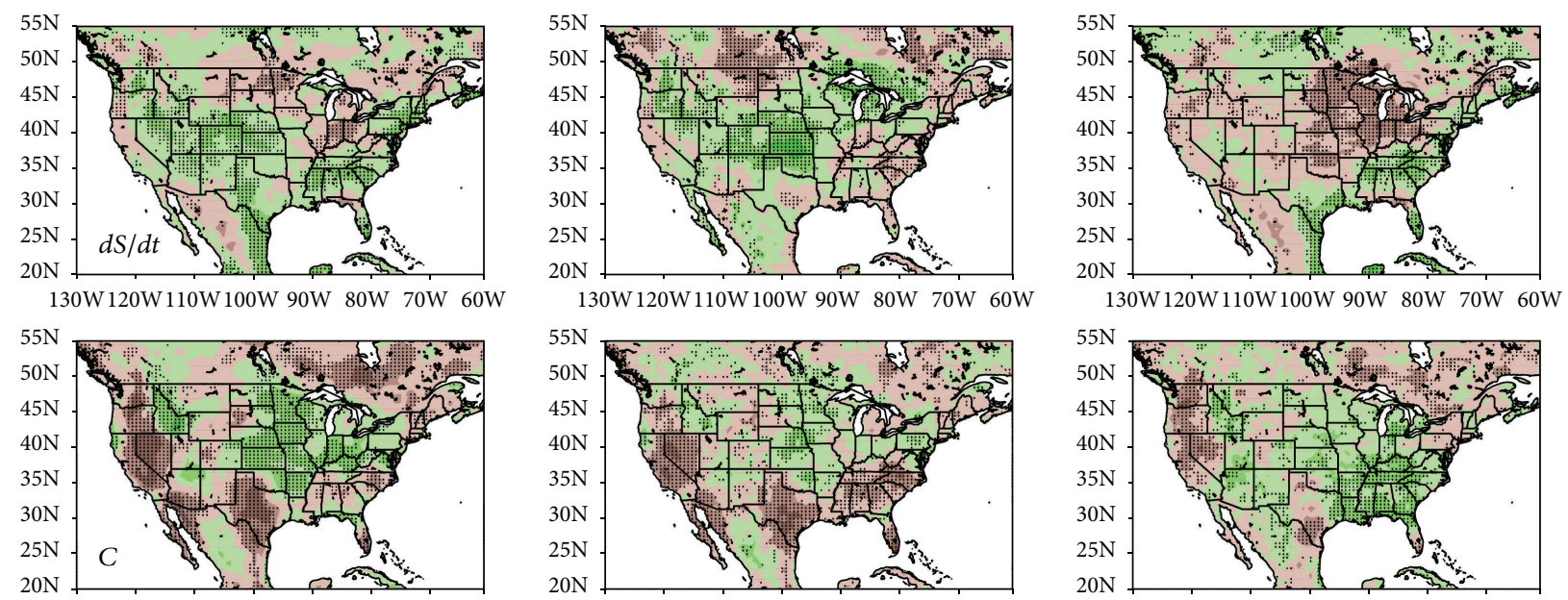

130W 120W 110W 100W 90W 80W 70W 60W
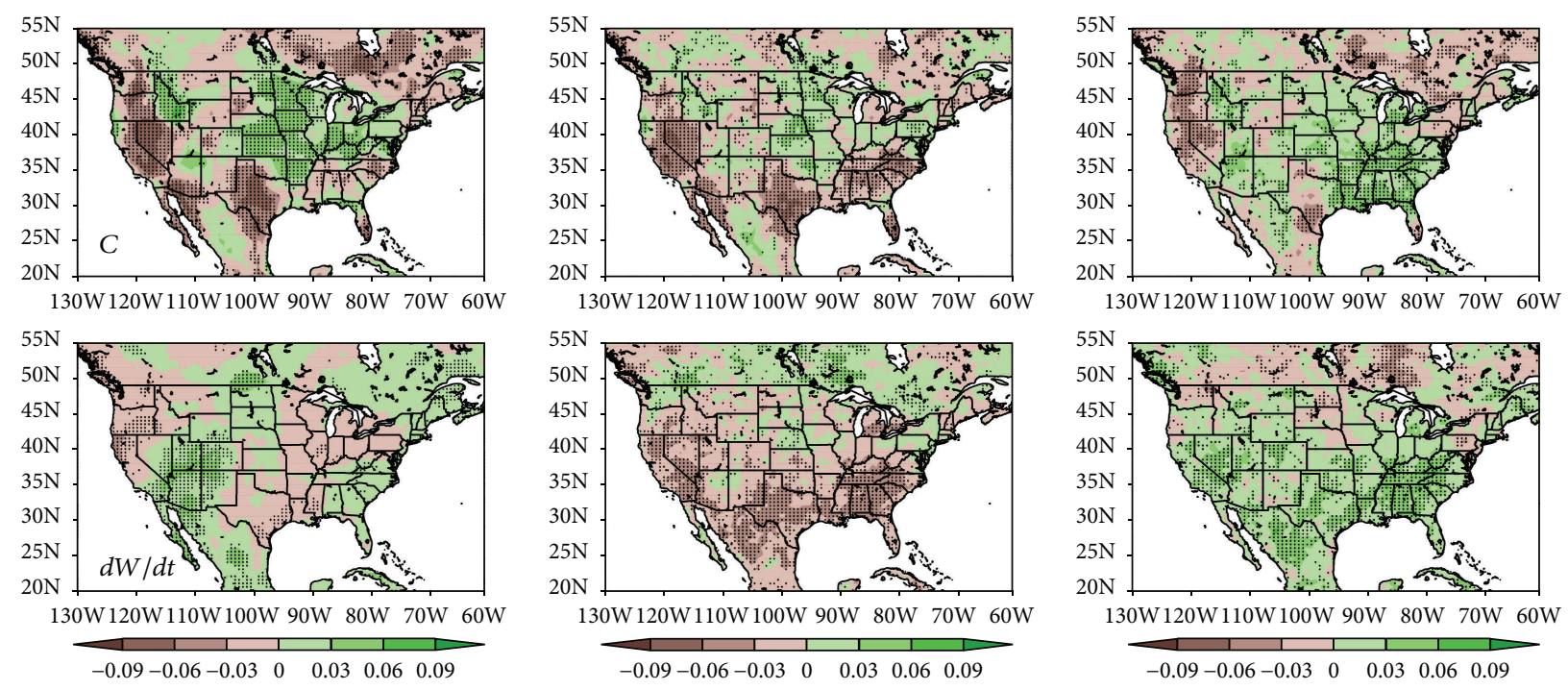

FIgURE 5: Same as Figure 1 but for summer. 

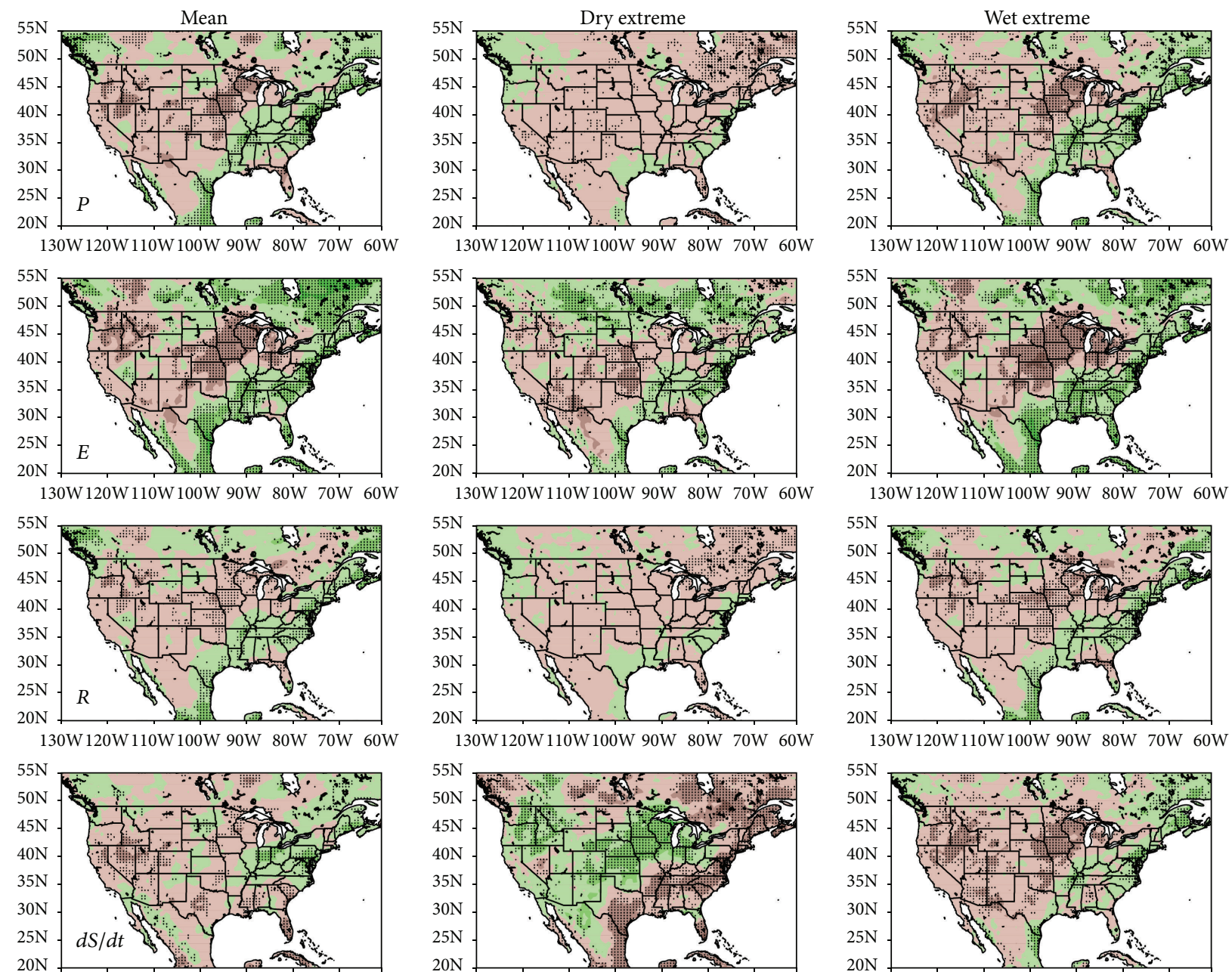

130W 120W 110W 100W 90W 80W 70W 60W
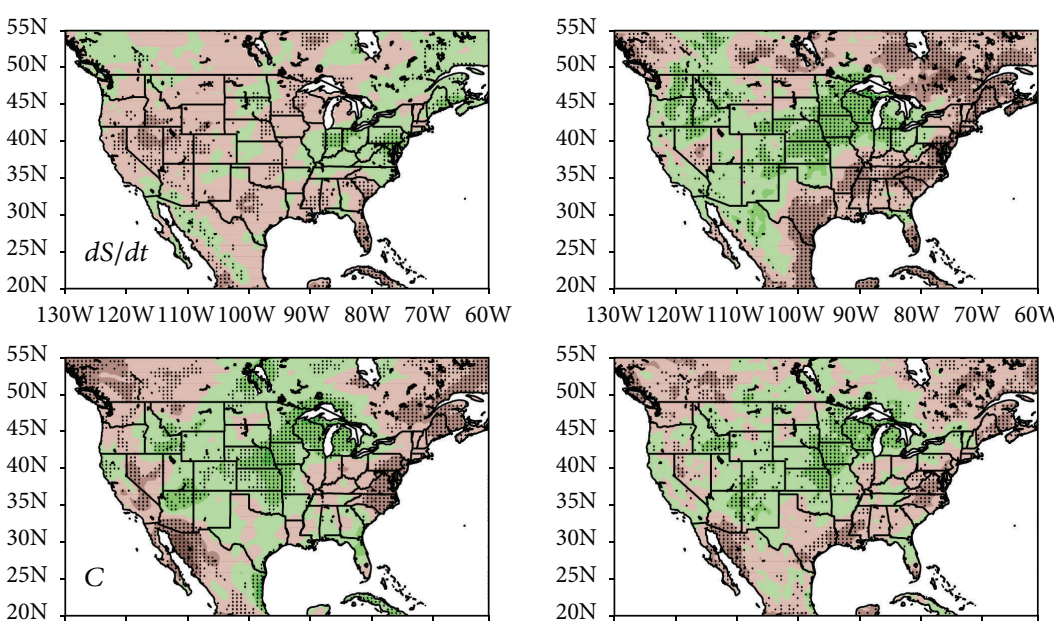

130W 120W110W 100W 90W 80W 70W 60W

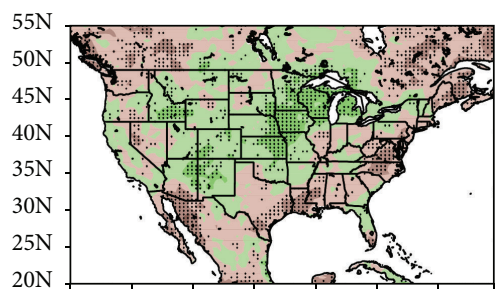

130W $120 \mathrm{~W} 110 \mathrm{~W} 100 \mathrm{~W} 90 \mathrm{~W} 80 \mathrm{~W} 70 \mathrm{~W} 60 \mathrm{~W}$

130W 120W110W 100W 90W 80W 70W 60W
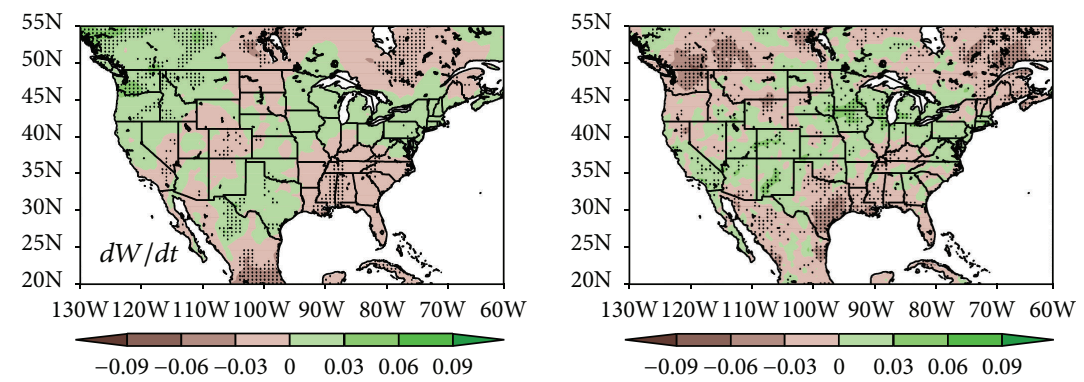

130W 120W 110W 100W 90W 80W 70W 60W

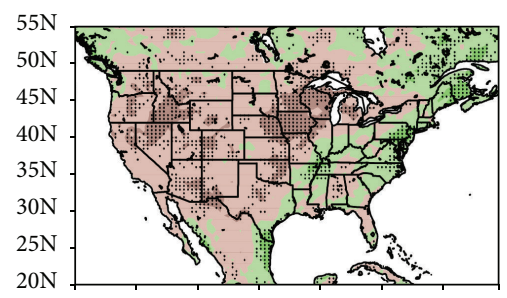

130W 120W 110W 100W 90W 80W 70W 60W

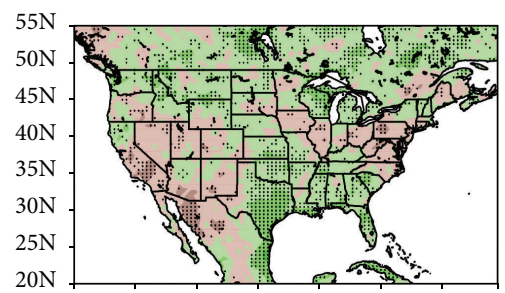

130W 120W 110W 100W 90W 80W 70W 60W

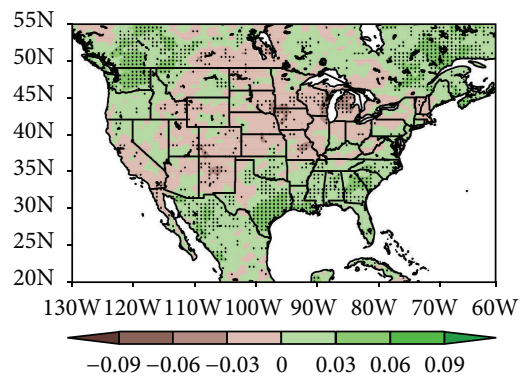

Figure 6: Same as Figure 1 but for fall. 

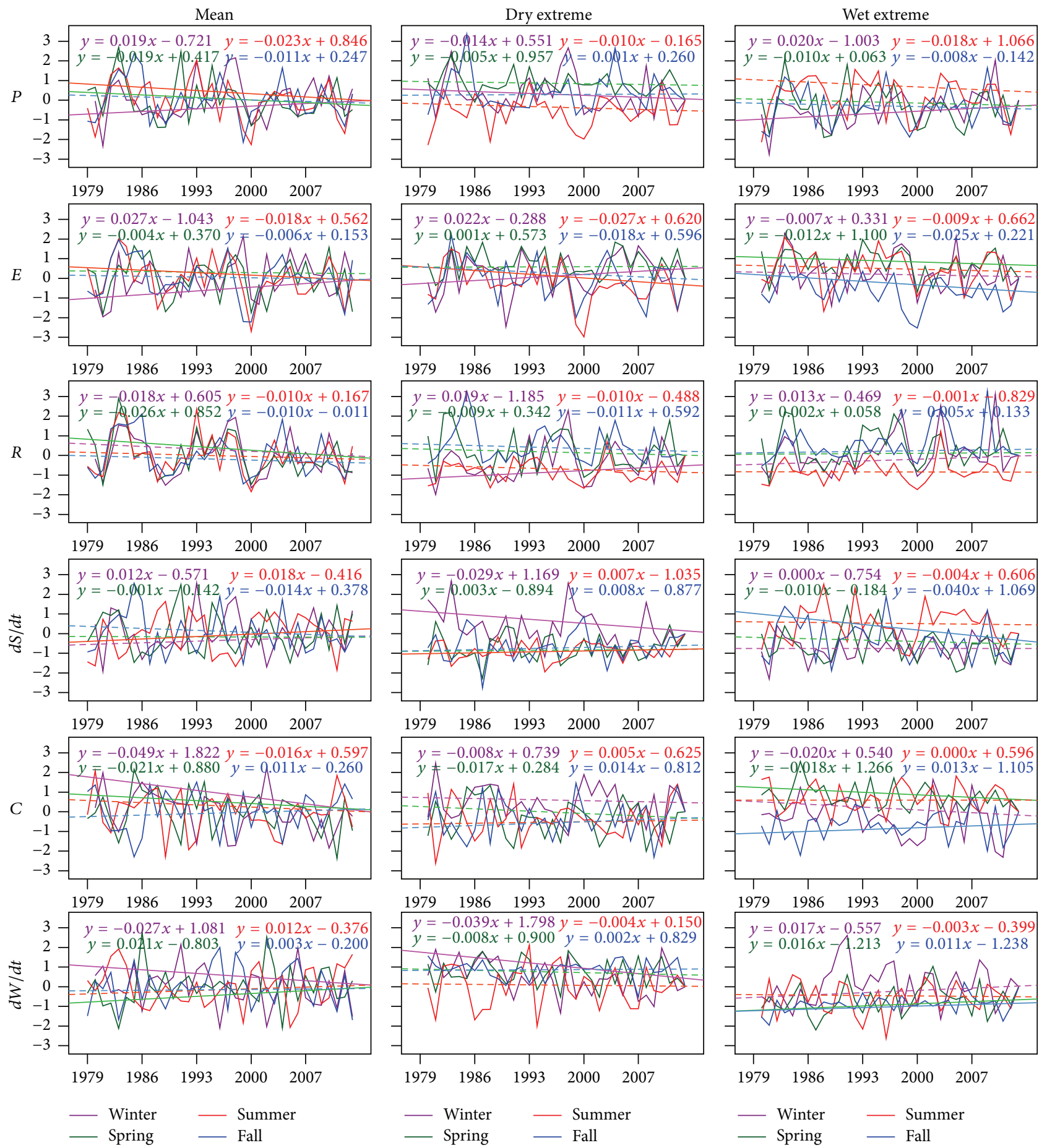

FIGURE 7: Same as Figure 2 but for winter, spring, summer, and fall, indicated by purple, green, red, and blue. The Kendall-Theil robust line is denoted by the same light color of the corresponding season.

\section{Conclusions and Discussions}

This study presented a suite of spatially and temporally scalable climate indictors to examine the long-term changes in water cycle variability across the CONUS over the period
1979-2013 using MERRA. The indicators consist of six water balance variables monitoring the mean conditions and extreme aspects of the following: precipitation, evaporation, runoff, vertically integrated moisture convergence flux, and terrestrial and atmospheric water storage changes. The means 

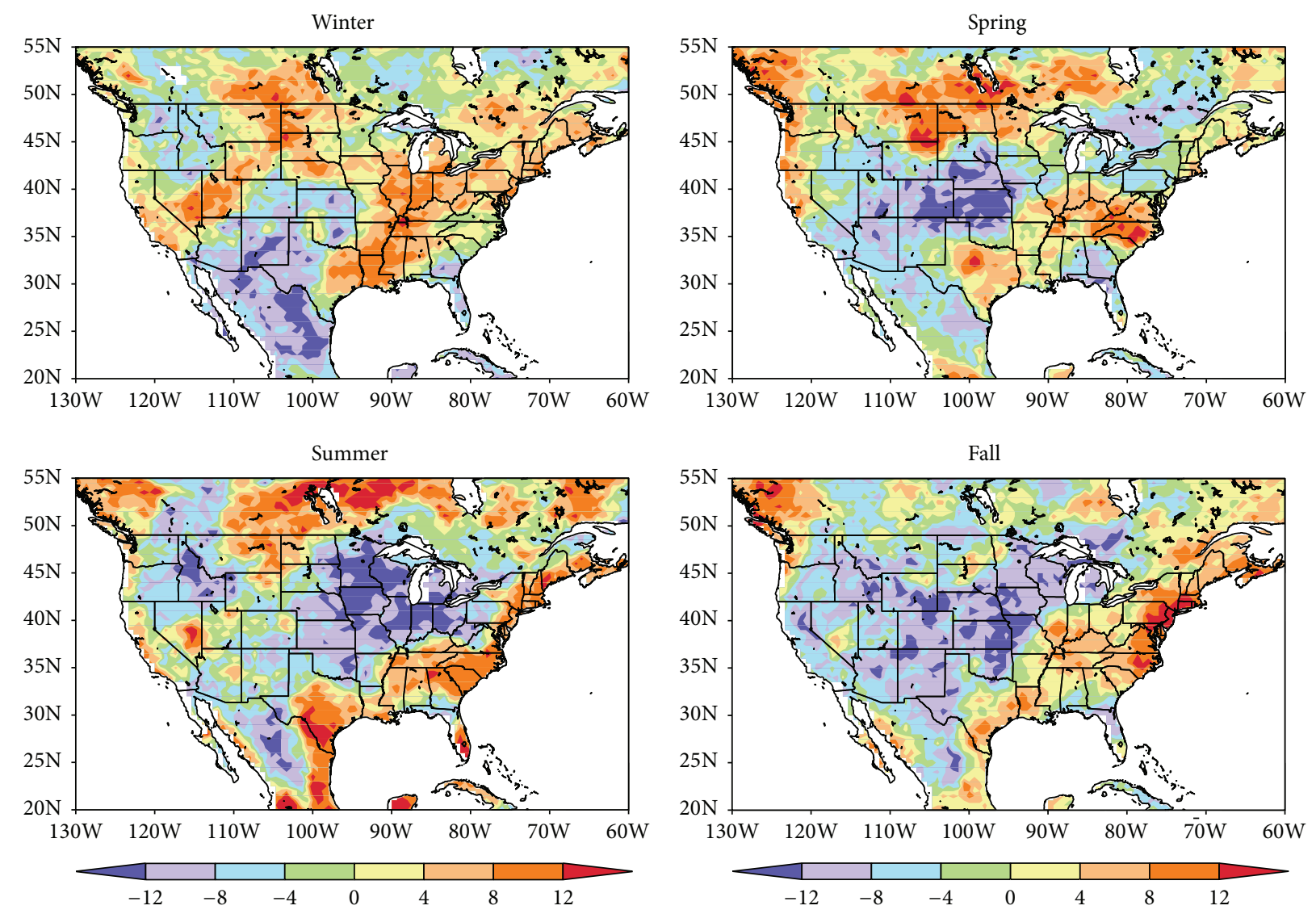

FIgURE 8: Same as Figure 3 but for winter, spring, summer, and fall.

are defined as daily total value, while extremes are determined as upper (wet) and lower (dry) tails of daily distribution based on the 10th percentile value.

Trends and statistical significance are estimated for annual and seasonal indicators across different spatial scales. The annual analysis found statistically significant increase along northeast, southeast, west north central, and northwest coastal areas of the CONUS but significant decrease over the remaining country in most of $P, E$, and $R$ indicators during the 35 -year period. The significant increase in $C$ indicators was detected over much of central and southwest with a large portion of the eastern coast regions showing more positive changes for wet extreme. Throughout the country, these four indicators generally have more significant negative changes than significant positive changes, which is also reflected in their averaged time series showing decreasing trends except in $R$ and $C$. The mean $d S / d t$ and $d W / d t$ indicators do not show significant changes although the patterns are mixed, consistent with their smaller national trends. The opposite changes have been observed in extremes for both $d S / d t$ and $d W / d t$ as evident from the corresponding spatial pattern and temporal variability. The results also reveal that the national trends in means are greater than trends in dry extremes except in $R$ and $d W / d t$ and smaller than trends in wet extremes except in $C$ although most of these trends are not statistically significant.
In general, there are statistically significant correlations between the trends in means and extremes across the country. The spatial correlations between trends in extremes and trends in means are stronger for $P, E$, and $R$ than for $d S / d t$ and $d W / d t$. Trends in $P, E$, and $R$ means are highly correlated with the corresponding wet extremes than the corresponding dry extremes, while mean $C$ has higher correlation with dry extreme than wet extreme. The strong relationship between the trends in means and extremes implies that the same driver is responsible for the long-term changes of means and extremes.

A partition of entire dataset between 1979 and 2013 into two equal time periods suggests that the probability distributions of all eighteen indicators are significantly different between 1979-1995 and 1996-2012 over the nation. The $P$ indicators exhibit a tendency toward drying conditions in mean associated with shift toward less intense extremes in the most decade. The distributions for $E$ indicators show shift towards decreased mean and wet extreme along with increased dry extreme. There is also visible reduction in the mean and extremes of $R$ during 1996-2012 compared to 19791995. For $d S / d t, C$, and $d W / d t$, apparent shifts are observed in the distributions of mean and extremes.

Seasonal trends show similar patterns to those observed in annual results but with different magnitude and statistical significance. For instance, annual trends of $P$ and $E$ mostly 

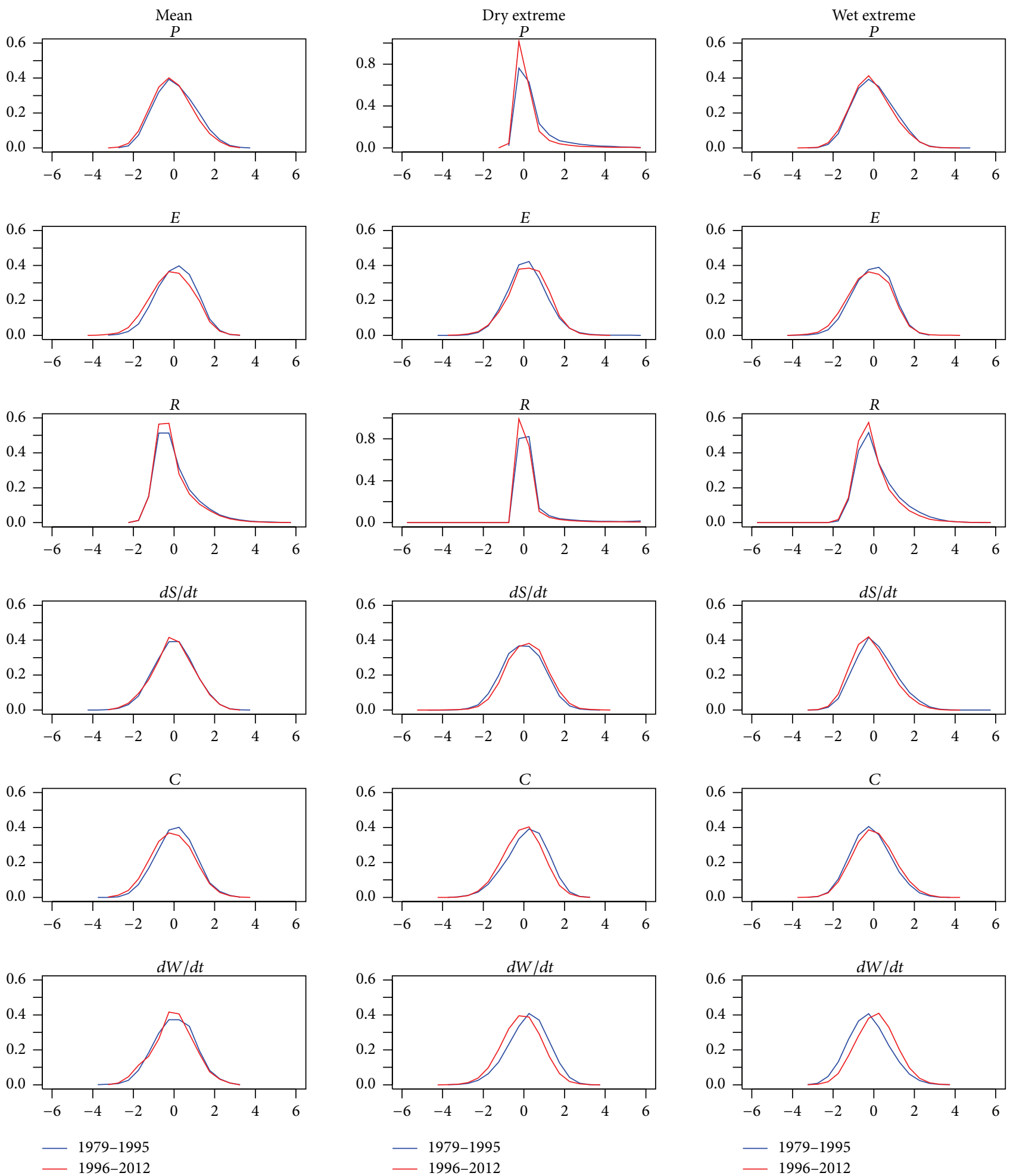

FIgURE 9: Annual probability distribution functions for mean, dry extreme, and wet extreme WCI indicators of $P, E, R, d S / d t, C$, and $d W / d t$ over periods 1979-1995 and 1996-2012.

resemble the changes in fall, while annual patterns of $R$, $C$, and $d W / d t$ are more consistent with summer changes. The most significant changes occur in summer whereas the least significant changes tend to occur in fall. Overall, there are more positive national trends than negative national trends in winter and fall where each of $P, E, R$, and $d S / d t$ indicators exhibits at least two upward trends. Seasonally, trends in means are highly correlated with trends in extremes 

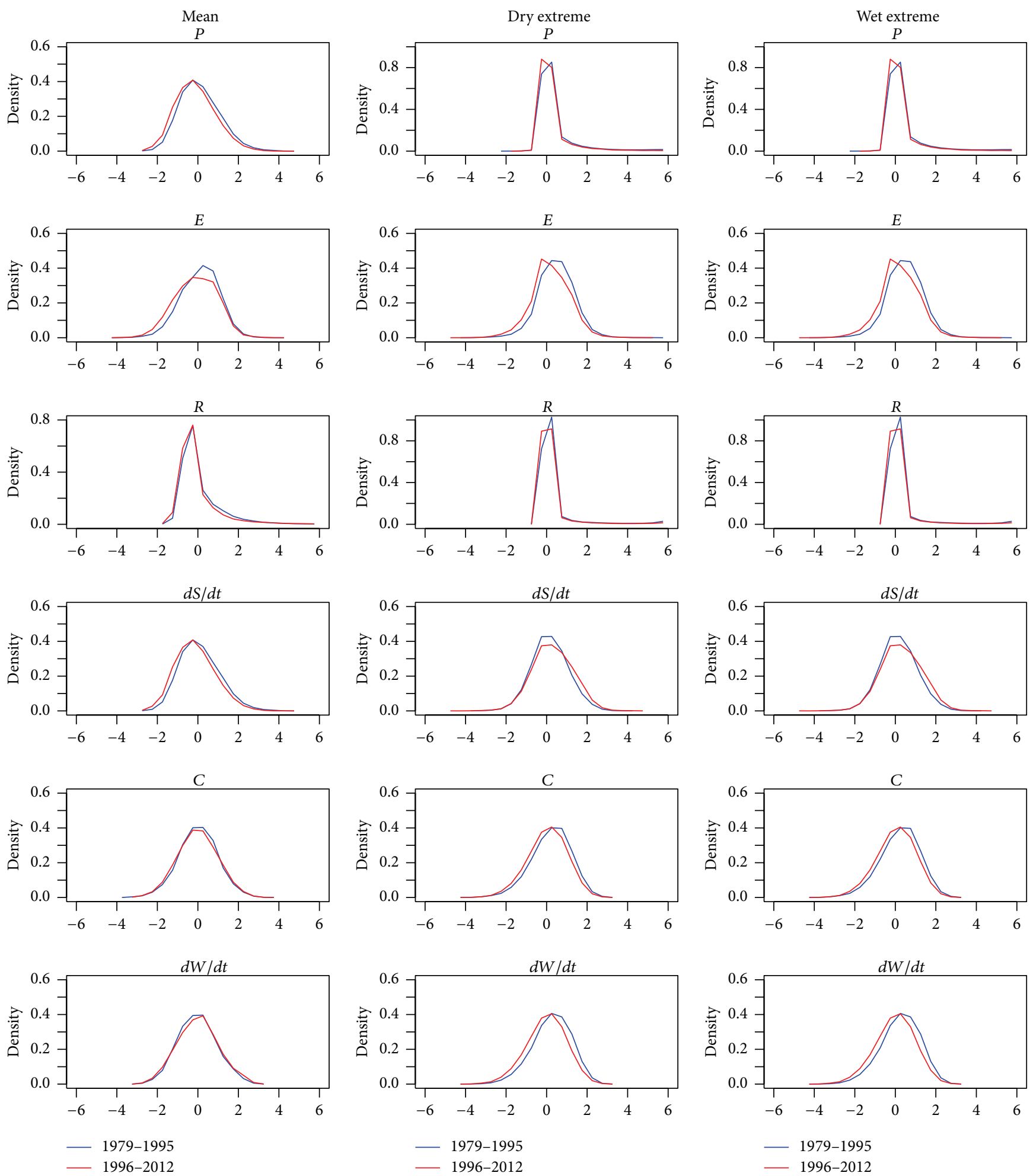

FIgURE 10: Same as Figure 9 but for summer.

except for $d W / d t$ which has smaller and even nonsignificant correlation coefficients. Summer has the most pronounced changes in the probability distributions while the least changes appear in fall.
It is worthy to mention that the changes in the water cycle could pose a significant challenge to societies and ecosystems. For instance, as extreme precipitation increases, both dry and wet conditions can intensify, leading to prolonged drought 

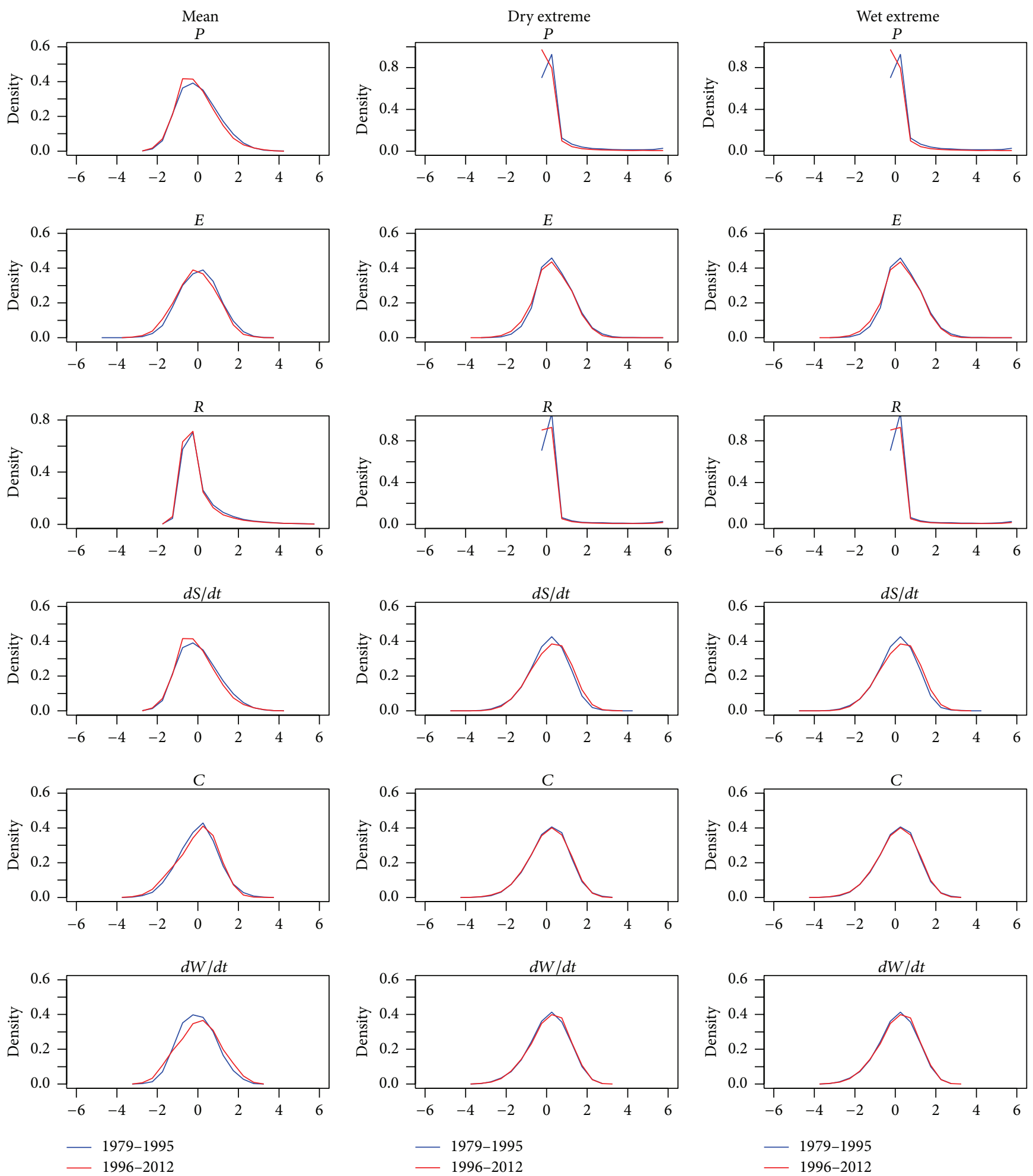

Figure 11: Same as Figure 9 but for fall.

or flash flooding. Drought is one of the most costly natural hazards affecting agriculture crops, vegetation cover, and water supplies. On the other hand, heavy rainfall increases runoff and can destroy infrastructure, contaminate water bodies, and threaten public health.
The indicators proposed in this study are valuable in monitoring regional and global changes in water cycle variability. However, the results from reanalysis data should be interpreted with caution. Reanalyses are essentially model output constrained by available observations. Variables such 
as precipitation are usually not directly assimilated to the forecast model. Furthermore, reanalyses are subject to inhomogeneities due to changes in the satellite observing system. These issues may affect the estimated trends in mean and extreme indicators presented here.

Our results cannot be directly compared with the previous trend analysis [26-28] as they use station data with different time periods based on different methodology. On the other hand, the station data only represent the value of a point location, while the reanalysis data are representative of the area average of a grid. In addition, in situ observations are often affected by the changes in observation time, instrumentation, and station location. Therefore, there is need to develop the effective approaches for comparing the trends derived from station and reanalysis data. Such comparison is useful for improving the representation of relevant processes in reanalysis products.

\section{Conflict of Interests}

The authors declare that there is no conflict of interests regarding the publication of this paper.

\section{Acknowledgments}

This work was supported by the NASA Grant NNH12ZDA001N-INCA. The authors thank Mbongowo Mbuh and Ako Heidari for helping downloading the MERRA reanalysis data and providing mask file for the CONUS.

\section{References}

[1] IPCC, "Summary for policymakers," in Climate Change 2013: The Physical Science Basis. Contribution of Working Group I to the Fifth Assessment Report of the Intergovernmental Panel on Climate Change, Cambridge University Press, Cambridge, UK, 2013.

[2] H. A. Loaiciga, J. B. Valdes, R. Vogel, J. Garvey, and H. Schwarz, "Global warming and the hydrologic cycle," Journal of Hydrology, vol. 174, no. 1-2, pp. 83-127, 1996.

[3] I. M. Held and B. J. Soden, "Robust responses of the hydrological cycle to global warming," Journal of Climate, vol. 19, no. 21, pp. 5686-5699, 2006.

[4] T. G. Huntington, "Evidence for intensification of the global water cycle: review and synthesis," Journal of Hydrology, vol. 319, no. 1-4, pp. 83-95, 2006.

[5] F. J. Wentz, L. Ricciardulli, K. Hilburn, and C. Mears, "How much more rain will global warming bring?" Science, vol. 317, no. 5835, pp. 233-235, 2007.

[6] M. Wild, J. Grieser, and C. Schär, "Combined surface solar brightening and increasing greenhouse effect support recent intensification of the global land-based hydrological cycle," Geophysical Research Letters, vol. 35, no. 17, Article ID L17706, 2008.

[7] T. H. Syed, J. S. Famiglietti, D. P. Chambers, J. K. Willis, and K. Hilburn, "Satellite-based global-ocean mass balance estimates of interannual variability and emerging trends in continental freshwater discharge," Proceedings of the National Academy of Sciences, vol. 42, no. 17, pp. 916-917, 2010.
[8] P. J. Durack, S. E. Wijffels, and R. J. Matear, "Ocean salinities reveal strong global water cycle intensification during 1950 to 2000," Science, vol. 336, no. 6080, pp. 455-458, 2012.

[9] A. G. Pendergrass and D. L. Hartmann, "Global-mean precipitation and black carbon in AR4 simulations," Geophysical Research Letters, vol. 39, no. 1, Article ID L01703, 2012.

[10] A. C. Janetos, R. S. Chen, D. Arndt, and M. A. Kenney, "National climate assessment indicators: background, development, and examples," Technical Input to the 2013 National Climate Assessment Report, Pacific Northwest National Laboratory, Richland, Wash, USA, 2012.

[11] T. R. Karl, R. W. Knight, D. R. Easterling, and R. G. Quayle, "Indices of climate change for the United States," Bulletin of the American Meteorological Society, vol. 77, no. 2, pp. 279-292, 1996.

[12] K. L. Gleason, J. H. Lawrimore, D. H. Levinson, T. R. Karl, and D. J. Karoly, "A revised U.S. climate extremes index," Journal of Climate, vol. 21, no. 10, pp. 2124-2137, 2008.

[13] M. Svoboda, D. LeComte, M. Hayes et al., "The drought monitor," Bulletin of the American Meteorological Society, vol. 83, no. 8, pp. 1181-1190, 2002.

[14] L. V. Alexander, X. Zhang, T. C. Peterson et al., "Global observed changes in daily climate extremes of temperature and precipitation," Journal of Geophysical Research, vol. 111, no. 5, article 109, 2006.

[15] V. V. Kharin, F. W. Zwiers, X. Zhang, and G. C. Hegerl, "Changes in temperature and precipitation extremes in the IPCC ensemble of global coupled model simulations," Journal of Climate, vol. 20, no. 8, pp. 1419-1444, 2007.

[16] X. Zhang, L. Alexander, G. C. Hegerl et al., "Indices for monitoring changes in extremes based on daily temperature and precipitation data," Wiley Interdisciplinary Reviews: Climate Change, vol. 2, no. 6, pp. 851-870, 2011.

[17] J. Sillmann, V. V. Kharin, X. Zhang, F. W. Zwiers, and D. Bronaugh, "Climate extremes indices in the CMIP5 multimodel ensemble: part 1. Model evaluation in the present climate," Journal of Geophysical Research: Atmospheres, vol. 118, no. 4, pp. 1716-1733, 2013.

[18] M. M. Rienecker, M. J. Suarez, R. Gelaro et al., "MERRA: NASA's modern-era retrospective analysis for research and applications," Journal of Climate, vol. 24, no. 14, pp. 3624-3648, 2011.

[19] F. R. Robertson, M. G. Bosilovich, J. Chen, and T. L. Miller, "The effect of satellite observing system changes on MERRA water and energy fluxes," Journal of Climate, vol. 24, no. 20, pp. 51975217, 2011.

[20] H. B. Mann, "Nonparametric tests against trend," Econometrica, vol. 13, pp. 245-259, 1945.

[21] M. G. Kendall, Rank Correlation Methods, Charles Griffin, 1975.

[22] D. H. Burn and M. A. Hag Elnur, "Detection of hydrologic trends and variability," Journal of Hydrology, vol. 255, no. 1-4, pp. 107-122, 2002.

[23] S. J. Wang, X. L. Zhang, Z. G. Liu, and D. M. Wang, "Trend analysis of precipitation in the Jinsha River Basin in China," Journal of Hydrometeorology, vol. 14, no. 1, pp. 290-303, 2013.

[24] N. W. Chaney, J. Sheffield, G. Villarini, and E. F. Wood, "Development of a high-resolution gridded daily meteorological dataset over sub-Saharan Africa: spatial analysis of trends in climate extremes," Journal of Climate, vol. 27, no. 15, pp. 5815$5835,2014$. 
[25] H. Theil, "A rank-invariant method of linear and polynomial regression analysis," Indagationes Mathematicae, vol. 12, pp. 8591, 1950.

[26] K. E. Kunkel, K. Andsager, and D. R. Easterling, "Long-term trends in extreme precipitation events over the conterminous United States and Canada," Journal of Climate, vol. 12, no. 8, pp. 2515-2527, 1999.

[27] P. Y. Groisman, R. W. Knight, T. R. Karl, D. R. Easterling, B. Sun, and J. H. Lawrimore, "Contemporary changes of the hydrological cycle over the contiguous United States: trends derived from in situ observations," Journal of Hydrometeorology, vol. 5, no. 1, pp. 64-85, 2004.

[28] T. R. Karl and R. W. Knight, "Secular trends of precipitation amount, frequency, and intensity in the United States," Bulletin of the American Meteorological Society, vol. 79, no. 2, pp. 231-241, 1998.

[29] P. Y. Groisman, R. W. Knight, D. R. Easterling, T. R. Karl, G. C. Hegerl, and V. N. Razuvaev, "Trends in intense precipitation in the climate record," Journal of Climate, vol. 18, no. 9, pp. 13261350, 2005.

[30] M. G. Donat, L. V. Alexander, H. Yang et al., "Updated analyses of temperature and precipitation extreme indices since the beginning of the twentieth century: the HadEX2 dataset," Journal of Geophysical Research, vol. 118, no. 5, pp. 2098-2118, 2013. 

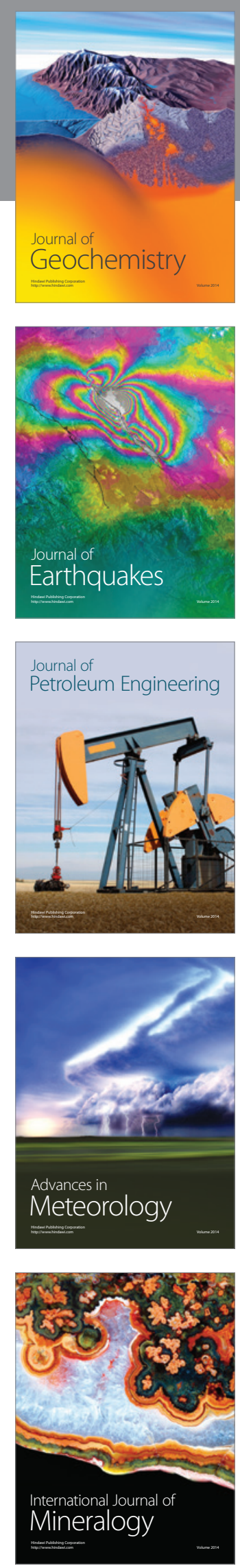
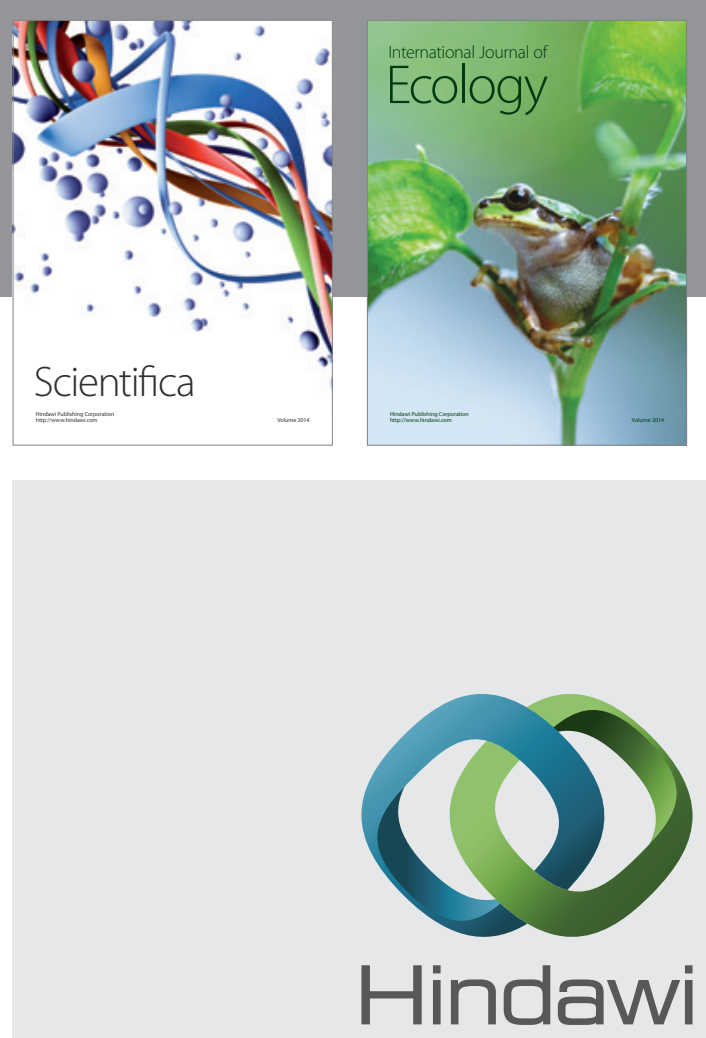

Submit your manuscripts at

http://www.hindawi.com
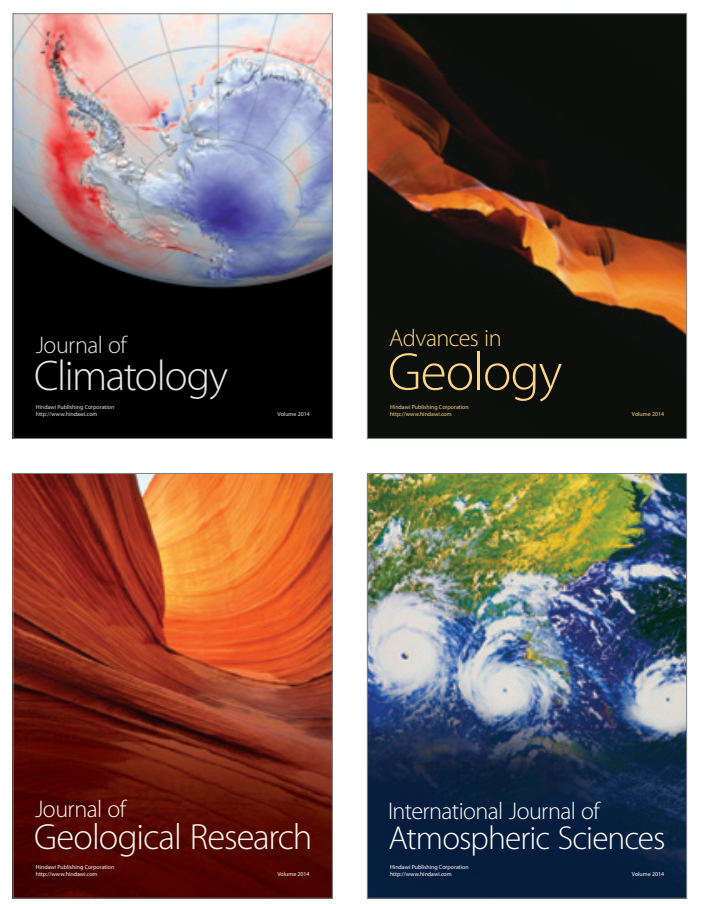

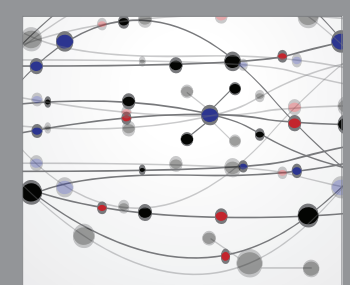

The Scientific

\section{World Journal}
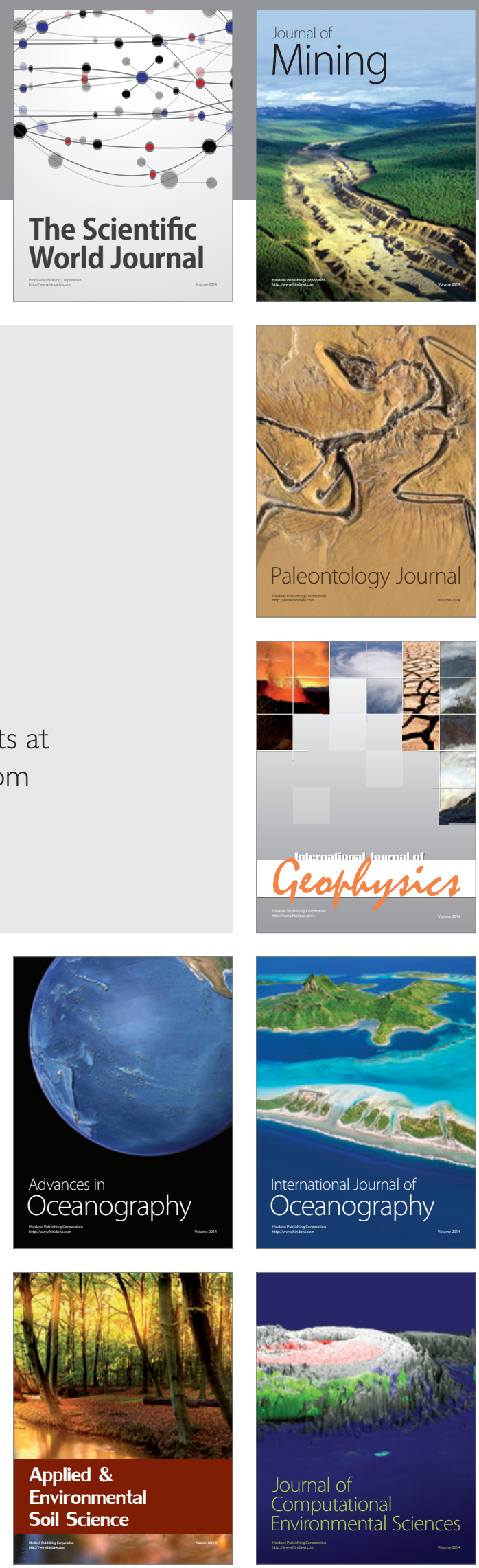